\title{
Defensas a la antigua y a la moderna en el Reino de Valencia durante el siglo XVI
}

\author{
LUIS ARCiniega García *
}

\begin{abstract}
RESUMEN
El presente articulo aporta documentación inédita sobre diversas obras de defensa llevadas a cabo en el Reino de Valencia durante el siglo XVI. Las noticias, interesantes por si solas, quedan insertas en un panorama amplio que permite entender la diversidad de sistemas defensivos como un medio de adaptación a las necesidades y los medios, rechazando el prejuicio que interpreta la pervivencia de la tradición exclusivamente como un rasgo arcaico.

Además se incide en la labor de ingenieros, militares y cargos de la administración en las realizaciones defensivas.

\section{ABSTRACT}

This article provides us with unpublished documentation about several defensive works Carried out during the Kingdom of Valencia, in the $X V I$ th Century. The information, interesting by itself, is inserted in a wide outlook that alhows to understand the diversity of defensive systems as a way of adapting to necessities and resources and rejects the prejudice that interprets the survival of tradition only as an archaic feature.

Futhermore, in the defensive works, the labour of engineers, soldiers and responsables of Administration is being emphasized.
\end{abstract}

El siglo XVi hispano es testigo de un cambio radical en la concepción militar. Los avances de las armas de fuego, que venian produciéndose desde mediados del siglo $x v$, condujeron a nuevas defensas y nuevos planteamientos de estrategia que fueron recogidos en los tratados de temas militares. Sirvan como ejemplo los estudios de Roberto Valturio (1472), Francesco di Giorgio Martini (c.a. 1480), Leonardo da Vinci (principios del XVI), Baldassare Peruzzi (primer cuarto del XVI), Durero (1527), Giovanni Battista

* Departamento de Historia del Arte. Universidad de Valencia. 
Bonadio de Zanchi (1554), Pietro Cataneo (1554 y 1567), Giacomo Lanteri (1557 y 1559), Girolamo Cataneo (1564), Carlo Theti (1569), etc. Por los nombres de los autores se intuye la procedencia geográfica de las inquietudes por los temas militares. Pero éste era un asunto demasiado universal para ser obviado en otros lugares. En la biblioteca de don Rodrigo de Mendoza, primer marqués de Cenete, se encontraban de rei militari instrumentis, Vegesius de re militari, Flavius Vegesius de re militari, en 1564 se encontraban en Valencia dos Vegetio y un Vallo libro de fortificar e una citade en italiano - muy probablemente los tres citados-; en la de don Fernando de Aragón, virrey de Valencia y heredero de los restos de la gran biblioteca de la Casa de Aragón en Nápoles, se encontraba el códice de Marcus Cinicus De re militari y la obra de Vegetius de igual título que la anterior; en la de doña Mencía de Mendoza, su segunda esposa y segunda marquesa de Cenete, los que poseyó su padre Rodrigo de Mendoza; mientras que en la de Jerónimo Eslava Carroz de Villaragut se hallaba una obra titulada Liber rerum militarum. En un nivel superior, la biblioteca de Felipe II contaba en 1576 con obras de Valturius, Durero, il vallo Toscane, Julio Florentino, Onosandro Platónico, Langeay y Vegecio. Algunas procedentes de las bibliotecas valencianas citadas ${ }^{1}$. Realmente el XVI hispano fue en su mayor parte deudor del pensamiento italiano en materia de defensa. La teoría a través de los tratados y la práctica a través de los ingenieros y arquitectos venian de Italia. Sólo al finalizar el siglo los españoles se incorporaron a esta tendencia. Cabe destacar en este sentido la labor de Cristóbal de Rojas en las cátedras de Fortificación y Geometria en la Academia de Matemáticas que Felipe II fundó en 1583, y cuyas enseñanzas quedaron fijadas en su Teoria y práctica de la fortificación, conforme las medidas y defensas destos tiempos, repartidos en tres partes (1598). Sólo un año más tarde Diego González de Medina Barba publicó su Examen de fortificación.

Las ideas, sin embargo, aunque disponibles no se aplicaron sistemáticamente, sino que las realizaciones por su elevado coste fueron muy selectivas. No debe interpretarse la pervivencia de los tradicionales sistemas de defensa como un arcaísmo, sino como una elección consciente acorde

Sobre estas bibliotecas pueden verse los siguientes trabajos, SANCHEZ CANTON, Francisco Javier: La Biblioteca del Marqués de Cenete, iniciada por el Cardenal Mendoza (1470-1523). 1942, Madrid. Marías Franco, Fernando: "Sobre el castillo de la Calahorra y el Codex Escurialensis", Anuario del Departamento de Historia y Teoria del Arte. 1990, vol. II, págs. 117-129. ARCINIEGA Garcia, Luis: "Conservación y dispersión del legado de la Casa Real de Aragón en Nápoles". Actas del XI Congreso Nacional de Historia del Arte. El Arte y el Mediterráneo. (Valencia septiembre de 1996) 1998, Valencia; págs. 114-121. AnDRES (O.S.A.), P. Gregorio de: “Entrega de la librería real de Felipe II", en Documentos para la historia del Real Monasterio de San Lorenzo El Real de El Escorial. 1964, Imprenta Sáez, Madrid; v. VII, págs. 13-233. 
a las necesidades que se pretendía atender y medios con los que se contaba para ello. El siglo xvı vivió una racionalización en la defensa que progresivamente llevó a concentrar los recursos en escasos puntos estratégicos. Su objetivo no era otro que repeler un gran ejército, entiéndase en el Reino de Valencia una gran armada en la mayor parte de la frontera: la costa. Aquí se introdujeron progresivamente los criterios de defensa más avanzados, los más caros; es decir, los abaluartados. Pero salvo este caso, las defensas eran modestas y atendian otros fines, otros enemigos.

\section{EL ENEMIGO EN CASA. LOS MORISCOS EN LAS SIERRAS DE ESPADÁN Y BERNIA, A MODO DE EJEMPLO}

Las poblaciones cercanas a la sierra de Espadán vieron seriamente amenazada su subsistencia por la presencia de numerosos moriscos levantados a partir de 1525 . El relato por excelencia de los hechos es el que aporta el cronista Gaspar Escolano ${ }^{2}$. Según éste, el detonante fue la cédula del 4 de abril de 1525, que reconocía los bautismos forzosos a mudéjares realizados durante las Germanias, y obligaba a convertirse al resto. Muchos se refugiaron en la sierra de Espadán. Carbau, vecino de Algar, que se hizo llamar Celim Almançor, se convirtió en su líder. La ciudad de Valencia se propuso reducirlos enviando al frente de la tropa a Pedro Çanoguer, señor de Alcácer, y como General a Alonso de Aragón, duque de Segorbe. Los insurrectos repelieron la agresión, y cuando se esperaba un ataque rebelde sobre la villa de Onda bajaron a Chilches, en el condado de Almenara, mataron a cinco personas que no pudieron huir, saquearon la iglesia y se llevaron el arca del Santo Sacramento con algunas formas consagradas. El Reino quedó conmocionado.

No deja de ser curioso comparar el diferente impacto que tuvieron en la sociedad valenciana dos actos muy cercanos en el tiempo: el pillaje a Chilches de 1526 y el Saco de Roma de $1527^{3}$. Por el primero, Valencia se

Escolano, Gaspar: Décadas de la historia de la insigne y coronada ciudad y Reino de Valencia. 1610-1611. Pedro Patricio Mey, Valencia; vols. II. Existe edición aumentada con notas, ampliaciones aclaratorias y continuada por Juan B. Perales, los datos de edición son 1878-1880, Terraza, Aliena y Compañia, Valencia-Madrid; vols. III. La narración de las luchas en la Sierra de Espadán puede verse en el libro $X$, capítulo XXVII, columnas $1.679-1.686$, y capitulo XXVIII, columnas 1687-1694. Recientes lecturas sobre la Guerra de Espadán y saqueo de Chilches se encuentran en PARDo MOlero, Juan Francisco: La revuelta de la Sierra de Espadán (1526). Tesis de licenciatura leida en 1992 en la Facultad de Geografia e Historia de la Universitat de València. PARDO MOLERO, Juan Francisco: La defensa del Imperio. Política militar en la Valencia de Carlos V. Tesis Doctoral leida en 1997 en la Facultad de Geografia e Historia de la Universitat de València; págs. 134 y ss. Véase el estudio de CHAStEl, André: El Saco de Roma 1527. (1983) 1998, Austral, Madrid. 
convulsionó, los corazones, como dice G. Escolano, se inflamaron. Las iglesias del arzobispado mostraron el luto cubriendo sus altares con telas negras, prohibiendo adornos, cerrando las puertas salvo las de las iglesias, alargando las procesiones, etc. Sólo en 1647 con la profanación en Paiporta los ánimos llegaron a tal extremo, aunque tal vez no durante tanto tiempo. Por el segundo, la culminación del conflicto que protagonizan Papado e Imperio, dos poderes, dos concepciones del Estado, y por el que las tropas de Carlos $V$ entraron a saco en Roma e hicieron huir al Papa, apenas se vertieron palabras. Parece que pasó, como es lógico, en silencio. Aunque más bien cabe suponer que fuera entre susurros, pues no cabe duda de que el cuestionar, aunque sea desde un punto de vista temporal, el papel del vicario de Dios en la tierra llevaría a algunas incertidumbres. Prueba de que no todo fue silencio es que el propio Virrey de Valencia, probablemente teniendo en cuenta los desmanes que las tropas del Emperador realizaban por tierras italianas, mandó traer desde Ferrara numerosas pertenencias que aún quedaban en poder de su familia. Con tal motivo, el día 1 de octubre se inició el inventario de aquello que debía enviarse a la ciudad del Turia ${ }^{4}$. Así como también lo es que Juan Ángel González, catedrático de poesía del Estudi General de Valencia en el coloquio introductorio de Eunuchus de Terencio, justificara con tanto empeño la política imperial y el Saco de Roma de 1527.

La Guerra de Espadán y el asalto a Roma llegaron a convivir, puesto que si bien en las sierras castellonenses los cristianos viejos, entre los que se encontraba como capitán Pérez Arnal, consiguieron sofocar los disturbios, muchos de los mudéjares y moriscos no conformes se desperdigaron y continuaron molestando a las poblaciones cercanas durante cierto tiempo. Una gran parte pasaron a Muela de Cortes, donde profanaron la iglesia. Tras un nuevo impulso de indignación cristiana otro correctivo aplacó los ánimos, aunque quedaron reductos y la sensación de inseguridad llevó a amurallar recintos pequeños que carecían de protección y se encontraban alejados de una verdadera frontera, como lo era la costa.

Las poblaciones más cercanas a Jérica eran las más próximas a la sierra de Espadán, y por lo tanto las más expuestas a los ataques de los moriscos insurrectos que alli se refugiaban. Jérica contaba con defensas desde antaño, a las que por otra parte habian contribuido las poblaciones de los alrededores en detrimento de las propias. Así se manifiesta por una orden real de 1371 en la que se convocaba a los síndicos de Jérica y lugares de su demarcación, para que dirimiesen sobre las murallas que debían realizarse en el centro de población más importante de la zona

Al respecto véase ARCINIEga Garcia, Luis: op. cit, 1998, Valencia; págs. 114-121. 


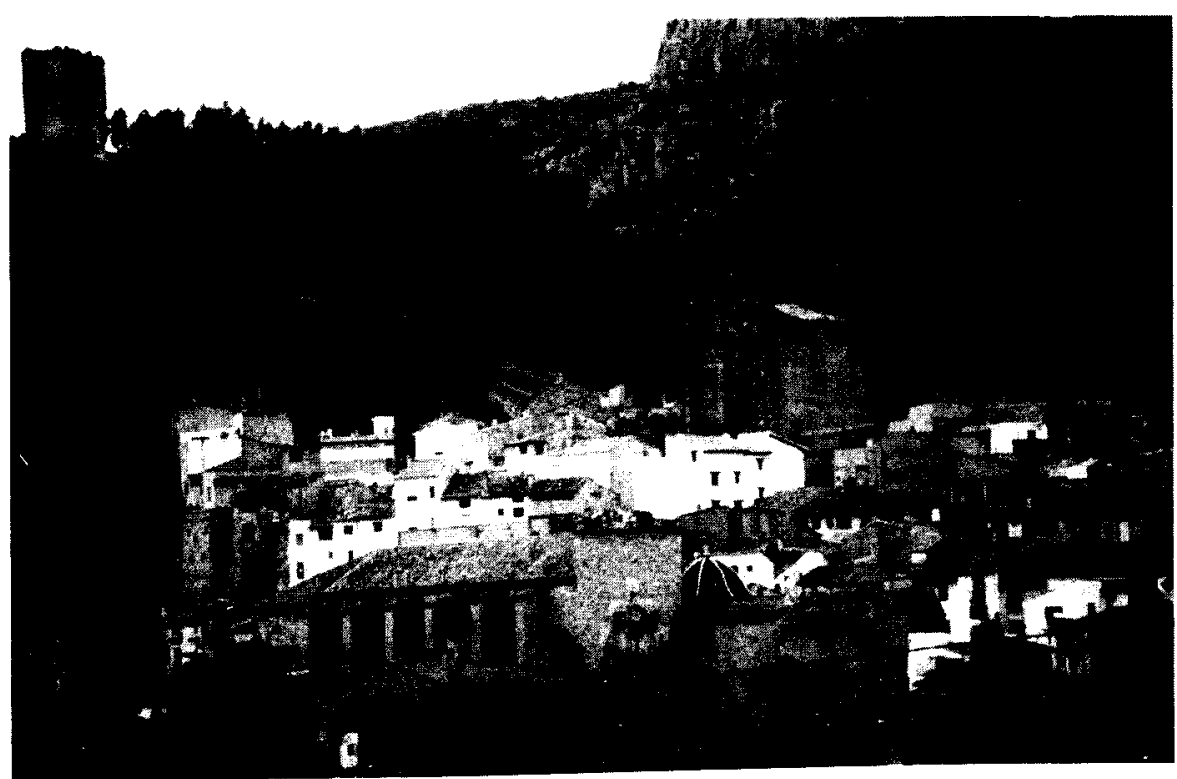

Figura 1. Vista de Jérica, población cercana a la sierra de Espadán, y restos de sus defensas.

(Figura 1). Esta responsabilidad fue recordada por Fernando II en 1488 cuando por orden real mandó a los vecinos de los lugares de Viver, Caudiel, Benafer y Novaliches, que siguiesen contribuyendo a las obras de las murallas de Jérica, según lo hacían desde tiempo atrás ${ }^{5}$. Pero la situación cambió desde los conflictos iniciados en 1525, haciéndose necesario extender la protección a los territorios circundantes. La familia Zarzuela tenía en señorío las villas de Toro y Caudiel, y lugares de Viver y Novalinches desde 1432, y tras la extinción de la rama masculina en el siguiente siglo, por vinculación matrimonial pasaron a don Jerónimo Pérez de Arnal, bayle de Teruel. Precisamente con él se comenzaron a construir defensas en las villas y lugares de los que era señor ${ }^{6}$. La más ur-

Archivo Servicio Histórico Militar de Madrid (=ASHMM), Sección Documentos, 2-1-5-41 y 2 1-3-59. Agradecemos esta noticia a Javier Ferreras Fincias.

La información la obtenemos de una serie de pleitos que se sucedieron durante más de cien años tras la venta de estos lugares a Fernando de Aragón, virrey de Valencia, y por los que los herederos de los vendedores reclamaron las mejoras que se realizaron en las propiedades a los herederos del comprador (Archivo del Reino de Valencia (=ARV), Clero, libro 1.067; ARV, Clero, legajo 696, caja 1.812; y ARV. Clero, legajo 712, caja 1.853, impreso en 1642, Juan Bautista Marçal, Valencia). Así como de otro que enfrentó al monasterio de San Miguel de los Reyes con la cartuja de Valdecristo, sobre la posesión de Toro, Viver, Caudiel y Novalinches 
gente y costosa fue la de las murallas de Caudiel, que vinieron a socorrer, en opinión de muchos testigos, las noches en las que bajaban los moros a instigar ${ }^{?}$.

Las murallas de Caudiel estaban formadas por tres puertas principales - correspondientes a los caminos de Valencia, Toro y el abrevadero-, y un pequeño portal en el camino de la marjal. Arcos de piedra tosca unían las dos torres de cada portal, y en cada uno de ellos había garitas de piedra picada. Además estaban recorridas por almenas. Eran de piedra en las cantonadas y mampostería en los lienzos, y median 488 paradas de largo, 20 palmos de alto, aunque en otras partes algo más, y 3 palmos de grueso. Mucho más tarde, durante las guerras carlistas de comienzos del XIX, fueron reformadas. Así lo indicaba Pascual Madoz, que al hablar de Caudiel decia: Se halla circunvalada de murallas bastante fuertes y elevadas para defenderse y librarse de una sorpresa, las cuales fueron edificadas por el duque de Calabria, entonces Sr. territorial, para impedir las últimas invasiones de los moros refugiados en los pueblos de la sierra Espadan: tiene 8 torreones á dist. proporcionadas para defenderla con sus fuegos oblicuos, habiendo sido reedificados en la pasada guerra civil, auxiliando la defensa el exconv. de Agustinos descalzos que se hizo fuerte por las tropas leales ${ }^{8}$. A comienzos del siglo $x x$ ya no se citaban estas defensas ${ }^{9}$.

Las primeras obras corrieron a cargo del cantero vizcaíno Gonzalo de Varrio Dejo (probablemente Barrio de Ajo) ${ }^{10}$, que el 25 de junio de 1529

(ARV, Clero, libro 108; loc. cit., 927 y loc. cit., 1.366. Se trata de tres libros iguales. En adelante sólo citaremos el primero).

ARV, Clero, libro 108, ff. 119-121

* Madoz, Pascual: Diccionario Geográfico Estadístico Histórico de España y sus Posesiones de Ultramar. 1846-1850, Madrid; vols. XVI. Nosotros utilizamos una edición limitada a la Comunidad Valenciana titulada Diccionario Geográfico - Estadístico- Histórico de Alicante, Castellón y Valencia. 1982, Institució Alfons el Magnànim, Diputació de València; vols. II. La cita se encuentra en t. I, pág. 274. Las murallas, como veremos, se realizaron antes de la adquisición de! lugar por el Duque de Calabria.

Carreras Candi, Francisco (Dir.): Geografia General del Reino de Valencia. 1913 (provincia de Castellón), Alberto Martín, Barcelona.

10 El nombre Barrio de Ajo presenta una gran variedad de posibilidades. Bien puede tratarse de un apellido perteneciente o relacionado con la casa infanzona de Barrio Ajo, como también lo es Vélez de Hontanilla, Camino, Cubilias o Isla. Las ordenanzas de la Junta de Siete Villas de 1572, citan como representantes a Juan Sáiz de Barrio de Ajo y a Francisco Sáiz de Barrio de Ajo, ambos vecinos del lugar de Ajo, y en 1594 se remató en Alonso de Barrio de Ajo la obra de cantería de la iglesia parroquial de su pueblo natal en 2.190 libras (POLO SANCHEZ, J.J.: «lglesia columnarias en la zona oriental de Cantabria». Arte Gótico Postmedieval. 1987, Segovia, pág. 96). Aunque también pudiera tratarse de un topónimo, siguiendo la tradición de cambiar el apellido cuando se mudaba de residencia. En el reconocimiento de pago que firmó Gonzalo Barrio de Ajo figuraba como vizcaíno. Ésta era una procedencia imprecisa que comprendia gran parte de la zona norte de la peninsula. Probablemente de tratarse de un topónimo responda al núcleo cercano al cabo de Ajo, en la 
declaró recibir de Jerónimo Pérez de Arnal, bayle de Teruel y señor de las villas de Toro y Caudiel en el Reino de Valencia, 15.210 sueldos de moneda jaquesa de Aragón, en parte de pago de los 34.610 sueldos por su trabajo en la muralla de Caudiel hasta el 20 de julio $1527^{\prime \prime}$. Los propios vecinos se encargaron de llevar los materiales, mientras que los señores pagaron los materiales, su trabajo y asentamiento ${ }^{12}$.

Cuando en 1527 el señor de Caudiel se quedó sin medios para continuar con los trabajos mandó hacer una información sobre la necesidad de concluir estas murallas que le permitiese argumentar la solicitud de una licencia para cargarse ciertos censos ${ }^{13}$. Melchor Bort, notario y procurador de Jerónimo Pérez de Arnal, expuso en la Corte del Gobernador, la conveniencia de acabar la muralla de Caudiel como defensa contra los bandoleros moros que quedaban en la sierra de Espadán, por cuya presencia la gente tenía miedo, pues era el núcleo cristiano más cercano y había precedentes de saqueos en otras villas o lugares, como Vilamalur o Torralba, donde entraron en sus iglesias y las saquearon. Pero la defensa contra simples bandoleros no era la única razón argumentada, pues también se señalaba su conveniencia para poder cerrar el lugar en tiempos de peste $e$ de altres necessitats les quals son remediades ab semblant clausura de mur e de portals e portes. Durante el mes de agosto varios testigos que bien habian habitado en Caudiel, o bien conocian el lugar porque participaron en sofocar la guerra en la sierra de Espadán, corroboraron que la dita muralla es molt utilitosa e profitosa per al dit lloch no sols en temps de guerra mas encara en temps de peste. Este mismo mes se nombró a Juan de Játiva y a Jaime Jover, experts en lo

entrada oriental de la bahia de Santander, perteneciente a la Junta de las Siete Villas. La villa de Ajo, dividida en barrios que llevaban los nombres a su vez de familias, tenía un barrio llamado Barrio de Ajo. A esta segunda opción responde Alonso Barrio de Ajo, que por un certificado de defunción, sabemos que su primer apellido era Fernández (ARCE OLIVA, Ernesto: "Notas para la biografia artistica del cantero Alonso Barrio del Ajo", Teruel, 79 (II). 1989; págs. 123-136). Pero, además, en el reconocimiento de pago firmado por Gonzalo Barrio de Ajo indicaba que era vecino de Teruel. Hasta el momento, la fecha más temprana de su actividad en la zona aragonesa más meridional se limitaba a su participación junto a Rodrigo de Utines en el coro de la catedral de Albarracin, entre 1538 y 1541, siguiendo probablemente trazas de Martín de Castañeda. Fecha que, por tanto, debemos adelantar con seguridad a 1529, y que con probabilidad sea anterior a 1526 si tenemos en cuenta que el comitente de la obra de Caudiel era bayle de Teruel.

ARV, Clero, legajo 696, caja 1.812. Contenido en «Sobre la averiguación y liquidación de las mejoras que el monasterio de San Miguel de los Reyes hizo en las villas de Toro, Viver y Novalinches en vista de la real Sentencia que se dio en favor de doña Ana Zarzuela", que recoge diversos papeles cosidos y foliados; concretamente ff. 550-554.

ARV, Clero, libro 108.

13 ARV, Clero, legajo 696, caja 1.812. Expone las mejoras realizadas por Jerónimo Pérez Zarzuela de Arnal y Violante Gasull. 
art, para que reconocieran la obra y determinaran lo que restaba por hacer y por cuanto.

Ante argumentos tan convincentes el 13 de febrero de 1528 el Gobernador dio licencia para que Jerónimo Pérez de Arnal pudiera cargarse 51.470 sueldos, 2.000 libras en propiedad, para acabar dicha obra. Pero esto no fue suficiente y el 15 de diciembre de 1535 se vio obligado a vender este censal a su hermano Juan a efecto de pagar ciertos canteros $y$ otros officiales, lo que havian trabajado en la muralla de Caudiel ${ }^{14}$. Entre los canteros, además de Gonzalo Barrio de Ajo, muy probablemente se encontrase Rodrigo de la Fuente, cantero vecino de Viver, que años después sirvió como testigo entendido en la obra ${ }^{15}$. La carga de los gastos era tal que en 1536 y 1538 se firmaron tres capitulaciones entre don Fernando de Aragón, duque de Calabria y virrey de Valencia, y Jerónimo Pérez de Arnal, su esposa Violante Gasull y el hijo de ambos Miguel Pérez de Arnal, sobre la venta de las villas y lugares de Toro, Viver, Caudiel y Novalinches, con derechos y rentas, jurisdicción civil y criminal. El reconocimiento de pago por la venta mantuvo el precio apuntado en las dos últimas capitulaciones; es decir, 28.528 libras, 5 sueldos. A finales de año Juan Pérez de Arnal se quitó el censal sobre el lugar de Caudiel ${ }^{16}$.

Las murallas de Caudiel en las que años más tarde se afirmó que el matrimonio se había gastado más de 3.000 ducados, no fueron las únicas que emprendieron los Pérez de Arnal en los territorios cercanos a la sierra de Espadán. Así, por ejemplo, también reedificaron la muralla del castillo de la villa de Toro e feren en ell una torre molt bona y molt vistosa y altres obres de molta utilitat, gastando más de 2.000 ducados. Pasado el ecuador del siglo el clérigo Miguel Sebastián testificó que se trataba de una torre cuadrada de piedra que se inició en 1530 , que según algunos fue construida sobre una media torre comenzada desde tiempo antiguo, y que en ese momento quedaba poco para acabarla. De mayor autoridad era la opinión de cantero Rodrigo la Fuente, pues manifestó que en el año señalado, junto a otro cantero, forró una torre muy vieja que había dentro del

Archivo Histórico Nacional (=AHN), Códices, 522/B, pág. 221.

ARV, Clero, libro 108, ft. 119-121.

Fernando de Aragón, por voluntad testamentaria, transmitió en 1550 los lugares citados junto al castillo y villa de Jérica, los lugares de Pina y Barracas, y el castillo y villa de Manzanera, al monasterio jerónimo de San Miguel de los Reyes, en la huerta de Valencia, fundación del propio Virrey y al que nombró heredero universal de todos sus bienes. Sobre la formación del patrimonio del Duque de Calabria en lo referente a villas y lugares véase FULLANA, Luis: "Historia del monasterio de San Miguel de los Reyes", Boletín de la Real Academia de la Historia. 1936, t. 108, págs. 274-278. Con ciertas diferencias véase también: AHN, Códices, 522/B, págs. 178-180, ARV, Clero, libro 1.373, y Biblioteca Valenciana (=BV), Nicolau Primitiu, mss. 290. 
castillo de Toro, alzándola por la parte de fuera 30 palmos, aunque no la acabaron totalmente ${ }^{1 ?}$. Por otra parte, en Novalinches el señor levantó un pueblo nuevo con su iglesia por 800 ducados, pueblo que según Rodrigo de Fuentes, en los treinta años que desde entonces habitó en la tenencia de Jérica lo habia visto continuamente destruido y derribado ${ }^{18}$, muestra de la retracción que producia un lugar sin defensas en un medio hostil.

Los tipos de obras defensivas que se realizaban en torno a la sierra de Espadán eran realmente acordes con las labores que se hacian en la época en el amplio espacio que la circunscribía. $Y$ no es que pronto dejaran de tener utilidad ante los nuevos usos militares, sino que nunca estuvieron destinados a ellos. Estas poblaciones reforzaron sus defensas buscando la protección contra los moriscos, y este problema pervivió durante largo tiempo. En febrero de 1545 el Virrey de Valencia presentó un proyecto para desarmar a este sector de la población, para cuyo fin presionó a los mayores señores de moriscos -duque de Segorbe, duque de Gandía y conde de Oliva-, y propuso llevar tropas a los puntos más conflictivos: Bernia y Espadán ${ }^{19}$. En diversas cartas procuró alimentar este temor. Así, por ejemplo, en carta al comendador mayor de León, de abril del mismo año, comunicaba las noticias que venían de Francia sobre las intenciones de enviar la armada de Barbarroja al Reino de Valencia, porque saben estaba a tan mal recaudo, assi de armas como de gente extrangera ${ }^{20}$. El proyecto no se llevó a cabo por discrepancias con los principales señores, y el propio Duque de Calabria aconsejó su descarte, pues con disensiones supondría la ruina del Reino. Sin embargo, parece que no cayó en saco roto la preocupación por controlar a los moriscos en los puntos más delicados, pues en octubre de 1561 el ingeniero Juan Bautista Antonelli inspeccionó las dos sierras citadas y realizó diversos informes ${ }^{21}$. Consistían en estudios que describían el terreno, los puntos de agua, los caminos, las poblaciones, etc. Además desarrollaba aspectos de estrategia

ARV, Clero, libro 108, ff. 124 y 126. El mismo cantero declaró que, junto a otro colega, realizó para la población de Toro un molino harinero.

ARV, Clero, libro 108. 1. 131.

HALPERIN DONGHI, Tulio: Un conflicto nacional: moriscos y cristianos viejos en Valencia. 1980, Institución Alfonso el Magnánimo, Valencia; pág. 165.

Archivo General de Simancas (=AGS), Estado, legajo 293, n. ${ }^{\circ} 91$. Carta del 4 de abril de 1545. Este sentimiento de considerar a los moriscos como extranjeros se repite constantemente.

Prueba de que en octubre de 1561 realizaba la visita la carta que se encuentra en AGS, Estado, legajo $329, n .^{\circ} 129$. Los informes en italiano se hallan en AGS, Estado, Legajo 329-I, números 35 a 38 . Los que tratan de Bernia, uno fue transcrito $\left(n .^{\circ} 38\right.$ ) y otro traducido ( $n .^{\circ} 37$ ) por PASton Fluixa, Jaume; CAMPON Gonzalvo, Júlia: Papers de Bèrnia (Documents i comentaris històrics sobre el fort de Bèrnia). 1986. Ajuntament de Callosa d'En Sarrià. Su trabajo también incluye los dos planos del fuerte que se encuentran en AGS, Mapas, Planos y Dibujos XIX- 63 y 96. 
militar, contemplando la defensa y en su defecto el ataque de estas montañas. En definitiva, el conocimiento del terreno permitiría su dominio. EI problema de los moriscos lejos de ser esporádico fue sostenido. Así lo reflejan las limitaciones a su movimiento (1559 y 1586) o a pescar (1560), su desarme $(1563,1567,1573,1575,1578$ y 1581), las medidas tras la rebelión de los de Granada (1568) y que en 1582 se volviese a tratar en la Corte su expulsión; hecho que se consumó en el siguiente siglo y reinado. La carta del 11 de septiembre de 1609 que envió Felipe III al Virrey de Valencia comunicando su decisión exponía los ofrecimientos de este sector de la población a los reinos e imperios musulmanes, a herejes y a monarquías rivales de la hispana. Según esta carta los moriscos ofrecían 150.000 hombres para pelear, en una empresa que por otra parte consideraban fácil por estar estos reynos muy faltos de gente de armas y exercicio militar ${ }^{22}$. Por ello no era infrecuente que en algunas poblaciones de gran presencia de moriscos la morería se encontrase fuera de las murallas.

Pero incluso tras la expulsión de los moriscos en 1609, estas obras continuaron teniendo una función. Ya hemos señalado como estas cercas servían para delimitar un espacio, que permitiria defenderse del enemigo y aislarse en tiempos de peste, pero también presentaban otros beneficios, como el ornamental y simbólico, resultado de configurar el perfil de la ciudad, como a finales del siglo xvI expuso Castillo de Bobadilla en su Política para corregidores (1597), contemporánea de la propuesta de Cristóbal Pérez de Herrera sobre la construcción de una muralla en Madrid ${ }^{23}$. Además, ni entre los moriscos sólo había ladrones, ni todos los ladrones eran moriscos, por lo que la inseguridad persistió. Camino de mediados del siglo XVII refiriéndose a Caudiel se advertía que la muralla les dejaba lliure de les inquietuts quels podia causar la gent inquieta y facinorosa de que no esta lliure la terra circumvehina. $Y$ ampliando el comentario a la villa de Toro se apuntaba: $Y$ quando se diga, que estos castillos y sus re-

\footnotetext{
22 Transcribe la carta del Rey PORCAR, Pere Joan: Coses evengudes en la ciutat y Regne de Valencia. (1589-1628. Mss.) 1934, Cuerpo facultativo de archiveros, bibliotecarios y arqueólogos, Madrid; vols. II. Transcripción y prólogo de Vicente Castañeda y Alcover. También 1983, Edicions Alfons El Magnànim. Institució Valenciana D’Estudis i Investigació, Valencia. "Colección: Biblioteca D'Autors Valenciana", n. ${ }^{\circ}$. Edición antológica. Introducción, selección y transcripción de la edición por Ferràn Garcia Garcia.

CÁmara MuÑoz, Alicia: "Murallas para la guerra y para la paz. Imágenes de la ciudad en la España del siglo xVI", Espacio, tiempo y forma. 1993, Serie VII: historia del arte, t. 6; págs. 149173. La autora transcribe un interesante texto con el que Pérez de Herrera defendía su propuesta de una muralla para honrar y adornar la villa de Madrid (nota 35, pág. 172). Entre los beneficios de las murallas citaba la defensa frente al enemigo y el aislamiento de las pestes; mientras que entre los que traia concentrar el acceso en escasas puertas señalaba el cobro de impuestos relacionados con el comercio, y la identificación de espías y delincuentes.
} 
paros no serían de provecho, pues que no se han edificado a la moderna. Se responde, que los antigos no pudieron prevenir lo que después han inventado los modernos, y no fuera razón dexar perder los dichos castillos, $y$ antes fuera peora, porque para conservarles basta que se juzgó en los tiempos antigos que se devian hazer ${ }^{24}$. Por tanto, no se podía argumentar despectivamente que estas obras estaban trazadas a la antigua, pues cuando se iniciaron no había otra alternativa -al menos en España-, y rechazaba su derribo, porque respondian a las necesidades que las dieron origen. Pero, ¿qué ocurrió tiempo después cuando realmente hubo alternativa? El análisis de la fortaleza de Bernia puede aportar bastante luz sobre ello.

Tras las revueltas de 1525 Bernia fue, junto a la sierra de Espadán, una zona conflictiva. Ya hemos visto como en ambas, aunque alejadas en el espacio, en 1545 el Virrey de Valencia proyectó defensas. En 1551 el canónigo Miguel Vich propuso reforzar las defensas de Benidorm por su cercanía al monte Bernia, inexpugnable y los moros otras vezes tentad

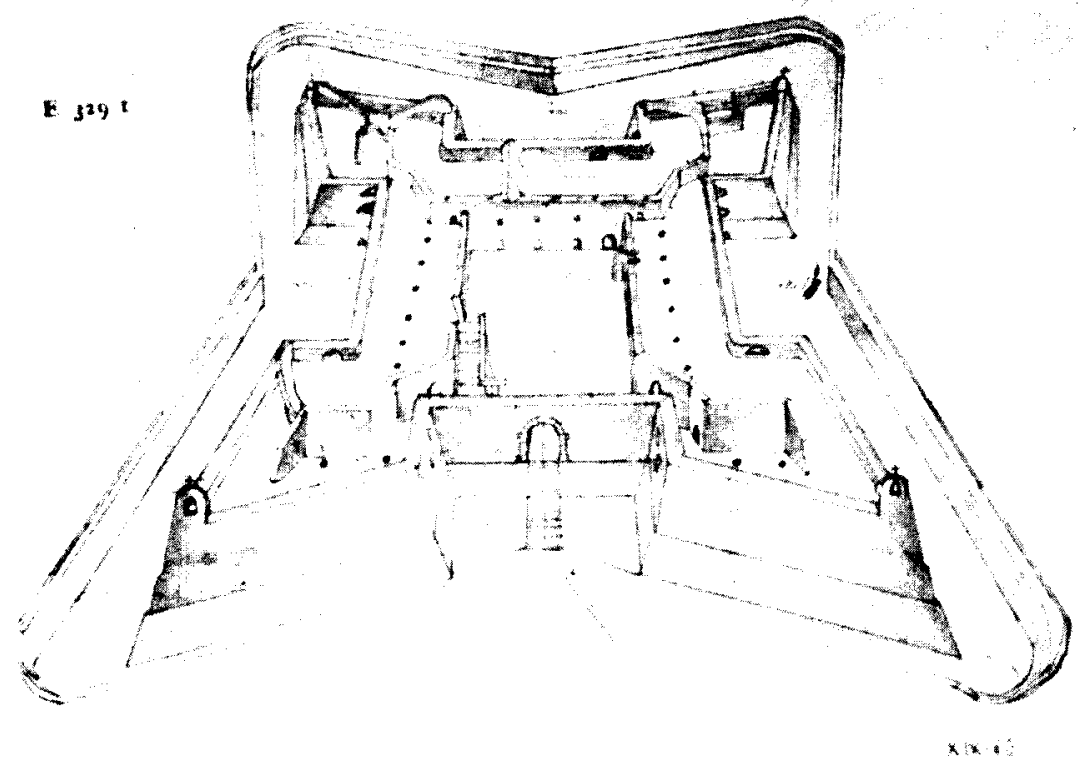

Figura 2. Plano de la fortaleza de Bernia en la sierra de su nombre (AGS, Mapas, dibujos y planos, XIX-63). 
de hazerse fuertes en él ${ }^{25}$. Finalmente, en octubre de 1561 el ingeniero italiano Juan Bautista Antonelli inspeccionó las sierras de Espadán y Bernia y proyectó una fortaleza en esta última teniendo en cuenta los tratados de arquitectura militar y soluciones prácticas de la escuela italiana de fortificación más en boga, iniciando en el Reino de Valencia la llamada fase abaluartada, caracterizada por el uso de formas estrelladas y baluartes triangulares (Figura 2). Esta obra se encuentra en la línea de obras más ambiciosas como la fortificación de Pamplona por Benedito de Rávena, Pizaño y Juan Bautista Antonelli, y continuadas en otras experiencias como la ciudadela de Pamplona por Giacomo Palearo Fratín, y la de Jaca trazada por fray Tiburcio Spanocchi, que también realizó las de la Aljafería de Zaragoza. Pero tuvo escasa fortuna ${ }^{26}$.

El 15 de abril de 1562 comenzaron las obras, que estaban bajo la dirección del propio ingeniero ${ }^{27}$. Por carta del 18 de junio el Rey instó a los capitanes Sancho de Ávila y Gonzalo de Palacios y al ingeniero Juan Bautista Antonelli a su rápida realización ${ }^{28}$. $Y$ así sucedió, puesto que a finales de agosto del mismo año encomendó una nueva misión a Juan Bautista Antonelli considerando que estaba a punto de finalizarse la obra. Los resultados fueron realmente desalentadores. Por una carta del 20 de junio de 1568 del Rey a su primo Antonio Alfonso Pimentel de Herrera, conde de Benavente, virrey y capitán general de Valencia, señalaba que había leído las cartas de mayo y junio que le había escrito, y en las que denunciaba que la fortaleza de Bernia estaba mal hecha desde el principio por haberse levantado en tan pocos días que no se secaron los cimientos y no se cubrieron algunas bóvedas por lo que con las lluvias se cayeron, y por lo que solicitaba que alguien entendido viese lo que debía hacerse. El Rey le tranquilizaba en su carta indicándole que por mandato suyo hizo que el ingeniero Luis Escrivá fuera a Bernia, y que éste ya habia mandado una relación de reparaciones que había sido aprobada ${ }^{29}$. Pero a todas luces el problema no era constructivo, sino más hondo. En 1575 el virrey de Valencia Vespasiano Gonzaga consideró que la obra no podia ser peor, por cuanto era totalmente desproporcionada a la finalidad con la que se hizo. No impedía

AGS, Estado, legajo 307, n. $^{\circ} 324$ y 341

Véase Pastor Fluixa, J.; Campon Gonzalvo, J.: op. cit.

Joan. Frances; March, Francisco; Yvars, Lucas (compiladores); Carreres Zacarés, Salvador (notas): Libre de memories de diversos sucesos e fets memorables e de coses senyalades de la ciutat e Regne de Valencia (1308-1644), amb una introducció i notes per Salvador Carreres Zacarés. 1930, Acción bibliográfica valenciana, Valencia.

AGS, Estado, legajo 141, $n .{ }^{\circ} 211$

AHN, Archivo de la Nobleza, Osura, legajo 419. $n .{ }^{\circ} 250$. Por este mismo fondo sabemos que Felipe 11 el 16 de agosto de 1567 mandó a Luis Escrivá trazar reparos en Játiva (n. ${ }^{\circ} 385$ ). 
el acceso a los moriscos a las fuentes de agua, exigía mucha dotación y gasto, y en caso de que ésta disminuyera corrían el peligro de que fuera tomada por el enemigo. Por estas razones propuso su derribo y substituirla por una torre, que sería suficiente contra los moriscos e incluso contra un gran ejército, pues sólo debía retenerlo hasta la llegada de refuerzos ${ }^{30}$. Y no fue el único, puesto que cinco años más tarde Fratín manifestó la misma opinión, en 1584 y 1585 eran necesarias obras, que se mantuvieron en el tiempo ${ }^{31}$, en 1587 el Consejo de Aragón propuso fortificar y poblar Altea y derribar Bernia, y tras la expulsión de los moriscos fueron más frecuentes las exposiciones en defensa de su derribo o disminución de su guardia. El 17 de julio de 1612 Felipe III ordenó su desmantelamiento.

El mismo problema fue atendido de dos maneras completamente diferentes. El éxito no dependía de la cantidad de dinero gastada, ni del conocimiento de las más modernas técnicas de fortificación militares, sino en la simple adecuación a las necesidades. En Espadán sencillas murallas de mampostería protegieron a las villas y lugares de los moriscos, en Bernia una costosa estructura abaluartada se hacía inútil poco después de finalizada, no por escasa sino por excesiva. Frente a los molestos huéspedes de la propia casa la modernidad no era por tanto garantía de eficacia; pero ¿y respecto a los temidos vecinos?

\section{EL ENEMIGO EN LA PUERTA. LA REALIDAD DE LOS CORSARIOS BERBERISCOS Y LA POSIBILIDAD DEL TURCO}

Durante el siglo XVı el Mediterráneo fue el punto de contacto de dos imperios, el otomano y el español, enfrentados por su control ${ }^{32}$. Aunque las costas españolas no fueron el campo de batalla de ambos, sus gentes estuvieron constantemente atemorizadas por la posibilidad de un ataque que, además, podía contar con el apoyo de la abundante población mudéjar primero y morisca después; e incluso padecieron los continuos ataques de corsarios berberiscos. Ésta fue la constante a lo largo del siglo, pero cada enemigo requería una defensa distinta. Utilizando las palabras del ingeniero Juan Bautista Antonelli Las ofensivas que tiene esta costa como las otras de esa

30 Transcrito íntegramente en MATEU IBARS, Josefa: Los virreyes de Valencia. Fuentes para su estudio. 1963, Ayuntamiento de Valencia; págs. 154-161 (procedencia AGS, Guerra Marina, legajo $79, \mathrm{n}^{\circ}$ 102).

31 ARV, Maestre Racional, $9.164,9.165$ y 9.259 .

32 Braudel, Fernard: El Mediterráneo y el mundo mediterráneo en la época de Felipe II. 1953 (Primera edición en francés en 1946, Armand Colin, París), Fondo de Cultura Económica, México. 
mar son o de corsarios que bengan a robar y saltear, o de armada que venga a tomar pie en ella o barrerla. Contra los primeros era suficiente aplicar la tradición, con murallas a la antigua, también llamadas de lanza y escudo, o contra corsarios, las mismas que se utilizaban para los moriscos; mientras que para los segundos debian tenerse en cuenta los nuevos y costosos avances en defensa, por lo que había que limitar su uso a los lugares donde realmente pudiera desembarcar el hipotético enemigo o fueran estratégicos. Al servicio de ambos se ponía una cuidada red de torres de vigilancia.

El 30 de agosto de 1503 los piratas argelinos atacaron y saquearon Cullera, gran parte fue incendiada, incluyendo la iglesia, y asesinaron y secuestraron a muchas personas ${ }^{33}$. El ataque causó un grave quebranto en la mentalidad de los valencianos, pues se trataba de una villa con buenas comunicaciones y próxima a la capital, y sin duda alimentó más aún el temor contra la comunidad islámica en tierras cristianas. Numerosas fueron las incursiones en diversos lugares de la costa. En 1532 Cullera padeció otra, que aunque de menor entidad fue suficiente para que en sta ocurrencia de temps de armades de moros e turchs enmichs de Nostra Sancta Fe Chatólica, Carlos V ordenase al virrey de Valencia que proveyese de armas y reparase su castillo. Al mismo ritmo se trabajó en Peñíscola, Valencia y Alicante, pero también en Castellón, Villajoyosa y Benidorm; incluso se autorizaron obras en el interior, como en Morella, Alpuente, Játiva y Onteniente ${ }^{34}$.

El temor a los insistentes ataques de piratas y a los rumores de uno mayor de armadas enemigas, como la del Turco, advertida por el Emperador en 1543, condujo en esa década a la intensificación en las obras de defensa y al abastecimiento de municiones. En 1544 se entendia con diligencia en la fortificación de Valencia con el maestro de campo Guevara, que pensaba bastarian las 12.000 libras sacadas de la Junta de

${ }^{33}$ Especificamente, sobre las defensas militares en el ámbito de Cullera y el contexto más amplio en el que se han desarrollado puede consultarse ARCINIEGA GARCiA, Luis: "Sistemas de defensa y vigilancia en Cullera: castillo, murallas y torres" (en prensa).

34 Requena Almoraga, Francisco: La defensa de las costas valencianas en la época de los Austrias. Memoria de Licenciatura leída en la Universidad de Alicante en 1990. Publicada en 1997. Instituto de Cultura "Juan Gil-Albert», Diputación Provincial de Alicante, Generalitat Valenciana. BeVIA I Garcia, Marius; Camarero CASAS, Eduardo: Arquitectura militar renacentista en la costa alicantina (siglo xvi). Proyectos y obras Mayores. Original mecanografiado. Conselleria de Cultura, Educació i Ciència de la Generalitat Valenciana, Departamento de Patrimonio, signatura 6.502/7. MARti FerRando, José: Poder y sociedad durante el Virreinado del Duque de Calabria (15361550). Tesis doctoral leída en la Facultad de Geografia de Historia de la Universitat de València en 1993; $t$ III, págs. 161-171. No citan, sin embargo, las obras de Cullera donde se gastaron unas 10.000 libras y quedan documentadas en ARV, Maestre Racional, 9.171 bis, ff. 17-18. 
Murs i Valladars. La traza de Guevara se conformó con los pareceres de don Juan Cervelló y del capitán Aldana en lo que a tiempo y dineros se refería ${ }^{35}$. Según Basilio Sebastián Castellanos, con documentos de archivo, las murallas de Gandía las compuso a su costa el duque de Gandia Pedro Luis de Borja (1468-1488), haciendo nuevo el lienzo de muralla que mira al este; es decir, al río de Alcoy. Francisco de Borja principió en 1543 el lienzo de muralla oeste, que concluyó en 1548, gastando en él, según consta en las cuentas, algo más de 11.502 libras, incluyendo en la obra el ensanche de dos calles. También reparó los muros viejos, gastando poco más de 603 libras, sin contar las reparaciones que hizo en la muralla del palacio. Por estas inversiones los escudos de armas de los Borja se encontraban en las puertas de la ciudad, aunque durante los movimientos revolucionarios de 1820 se picaron ${ }^{36}$. Francisco Gilabert de Centelles, conde de Oliva, emprendió los refuerzos de las villas de su condado como Oliva y Murla. Por una carta del 8 de marzo de 1544 se excusaba ante el Príncipe de no poder cumplir el mandato que recibió de acudir a Alzira para proveer la seguridad y defensa de la villa, pues se encontraba enfermo de gota y en mi ausençia pararían las obras de las nuevas fortalezas que se hazen en esta villa y en la de Murla, las quales son muy importantes para la dicha seguridad y deffensión ${ }^{37}$. Por dos inscripciones sabemos que las obras de Oliva finalizaron hacia 1545, y eran ampliación de las que hizo Serafín de Centelles, muerto en 1536; mientras que las de Murla pudieron finalizar hacia 1546. En Alzira, por su parte, tuvieron que realizarse obras importantes, pues en 1552 todavía se hacía un foso para adaptarla a la nueva realidad militar, lo que provocó que se cayeran varios lienzos de muralla ${ }^{38}$. En realidad, la actividad de fortificación tuvo que ser general, y así lo indica un acto notarial de 1547 que manifiesta la dificultad que había para encontrar gente de la construcción dado que tots los obrers de vila prengué Xàtiva y altres lochs del present Regne per a fortificar les terres per la armada de Barbarroja ${ }^{39}$. Esta demanda constituye

35 AGS, Estado, legajo 293, n. ${ }^{\circ} 65$ y 73 . El primer expediente corresponde a la carta de Fernando de Aragón del 26 de marzo de 1544. El segundo, a la carta del licenciado Gasca al señor comendador mayor de León, del 30 de abril de 1544.

${ }_{36}$ La Memoria de Basilio Sebastián Castellanos se encuentra en AHN, Archivo de la Nobleza, Osuna, Cartas, legajo 522, n. 8 (3). Pascual Madoz señaló poco antes la misma información, aunque sin mencionar la coritribución de Pedro Luis de Borja, y señalando que las libras gastadas por San Francisco de Borja fueron 11.552. Califica las murallas de fuertes y sólidas, de cal y canto, con 9 torreones, foso - por el este es el propio río Alcoy-y cinco puertas de entrada. Véase Madoz, Pascual: op. cit., t. I, pág. 355.

AGS, Estado, legajo 293, n. ${ }^{\circ} 147$.

AGS, Estado, legajo 309, n. ${ }^{\circ}$ 162. Carta del 12 de octubre de 1552.

39 Archivo de Protocolos del Colegio del Corpus Christi o Patriarca Ribera de Valencia (=APPV), Juan Bellot, 11.679; 22 de febrero de 1547. Acto referido a Ayelo. 
una de las razones de más peso para que maestros de otros ámbitos geográficos se establecieran en tierras valencianas.

En un ambiente ciertamente sensible a un ataque enemigo se entiende que en septiembre de 1547, en la celebración de Cortes Generales en Monzón, los tres brazos del Reino de Valencia expusieran al Príncipe de Asturias y Gobernador General de los Reinos de España su preocupación por la defensa de la costa. Específicamente solicitaron la mejora de las fortificaciones de Peñíscola y Villajoyosa, el envío a Cullera de tres o cuatro piezas de artillería, la construcción de una torre en el cabo de esta última población y otra en Oropesa que disuadiera a los corsarios que atacaban a los pescadores. El Príncipe proveyó al lugarteniente general para que determinase lo más conveniente en todos estos asuntos ${ }^{40}$.

Estas Cortes marcaron la inflexión en la consideración de las defensas de la costa del Mediterráneo peninsular. La idea de fortificar el litoral reemplazó a la corriente tradicional que perseguía la protección, sin mucho éxito, mediante galeras, bien de indisciplinados corsarios, bien a través de una armada regular bajo la dirección del Emperador ${ }^{41}$. Desgraciadamente para los de aquí las medidas no llegaron a tiempo y el 25 de mayo de 1550 el pirata Dragut Arrayz con veintiséis galeras y galeotas saqueó Cullera, sembrando el terror entre la población ${ }^{42}$. Ante esta situación las medidas se sucedieron. El Real Consejo aprobó el envío de veinte arcabuces y ocho jinetes de la guardia del Virrey, y el préstamo de una media colebrina. El virrey Fernando de Aragón redactó un memorial sobre la defensa de costa ${ }^{43}$.

40 Archivo Corona de Aragón (=ACA), Cancillería Real, n. $3.986, \mathrm{ff} .65-66 \mathrm{v}$.

Las decisiones de estas Cortes en materia defensiva fueron señaladas por GARCIA MARTíNEZ, Sebastián: Bandolerismo, piratería y control de moriscos durante el reinado de Felipe II. 1977, Universidad de Valencia; pág. 24.

41 PARdo MOlero, Juan Francisco: "Per terra e no per mar". La actividad naval en la defensa del Reino de Valencia en tiempo de Carlos I", Estudis. Revista de Historia Moderna. 1995, n. 21, págs. 61-87.

4: Joan, Frances; MarCh, Francisco; YVARs, Lucas (compiladores); CARREREs ZaCARES, Salvador (notas): op. cit., t. II, pág. 860. Aunque cita que el acontecimiento se produjo el día 20. También en DIAGO, Fray Francisco: op. cit., en concreto saca las noticias del dietario de Jacobo Ferrer, t. II, págs. 34-36. Señala: quedó la villa tal que en muchos años no pudo levantar cabeza. También lo recoge el mismo autor en t. II, pág. 123 en las noticias extractadas del Ex libro Memoriarum M.S recondito in sacristia sedis Valentiae. De igual modo es mencionado por VICIANA, Martín de: Tercera Parte. Crónica de Valencia. (1564) 1882, La Sociedad Valenciana de Bibliófilos, Valericia; pág. 411.

${ }_{43}$ PARDo Molero, Juan Francisco: La defensa del Imperio. Política militar en la Valencia de Carlos V. Tesis doctoral leida en 1997 en la Facultad de Geografia e Historia de la Universitat de València; págs. 306-307 y 308-311. El Virrey proponía enviar 50 arcabuceros y 10 jinetes a Benidorm, 15 jinetes al Júcar y 25 jinetes a Castellón. Además aconsejaba la fortificación de Villajoyosa y Cullera. 
El 15 de marzo de 1551 se expuso la necesidad de hombres a caballo para guardar la Marina y que convendria specialmente encargar lo que toca a la fortificación de Villajoyosa y Cullera porque el dicho Duque (de Calabria) dexo assentada la forma della, que es que los mesmos pueblos contribuyan en la metad y que la otra metad fuesse a cargo de la regia corte por ser lugares de realengo, y en haver fallecido dicho duque la cosa ha parado ${ }^{44}$. La intervención del Duque de Calabria, que murió pocos meses después del asalto de Dragut, indica la temprana intención de resolver la carencia de defensas. El 25 de junio de 1551 el Emperador comunicó al Gobernador de Valencia su deseo de que no se repitiesen los acontecimientos del año pasado. Al margen de la carta se apuntaba que ya se entendía con los de la Villajoyosa que el Rey diese 1.000 ducados. Lo mismo se quedó con los de Cullera, que en principio pretendian se pagase la mitad de los 5.000 en los que se estimaba la obra ${ }^{45}$. El 20 de julio, doña María, Reina de Hungría y Gobernadora del Reino por su padre el Emperador Carlos V, autorizó la fortificación de las poblaciones de Cullera y Villajoyosa, asignándoles caudales para hacerlo: 1.000 ducados ese mismo año y otros 1.500 el siguiente, para cada villa. Pero ni mucho menos con esto estaba cumplido todo. La Corona no disponía de medios para realizar las oportunas defensas en las villas reales, y muchos señores no estaban en mejores condiciones. En 1551 el Lugarteniente General de Valencia aconsejaba al Príncipe el derribo de Benidorm, por el mal estado en el que se encontraba. Sólo un año más tarde Juan de Villarasa recordaba a su Alteza todo lo que gastó en fortificarla y guardarla, y que bajo la propiedad de Alonso Fajardo todo esto se había descuidado y hasta los piratas habian entrado y quemado lo que quisieron ${ }^{46}$. Algo parecido se apuntaba con la torre de Oropesa de Juan de Cervellón, y con Denia, a cuyo Marqués se instaba continuamente a que fortificase el castillo de la villa que daba nombre al título.

Por comisión de los estarnentos y oficiales reales del Reino de Valencia, el canónigo Miguel Vich envió al príncipe don Felipe, a su regreso de Flandes, en septiembre de 1551 una exposición del estado en que se hallaban todas las villas y puntos fuertes del citado Reino, y de los medios necesarios para su defensa ${ }^{47}$. Peñíscola, Denia y Alicante eran los más im-

${ }^{44}$ ACA, Cancillería Real, Registros, $n .^{\circ} 4.282$, ff. $64 \mathrm{v}$ y $65 \mathrm{v}$.

AGS, Estado, legajo $307, \mathrm{n}^{\circ} 346$.

-6a carta del 8 de agosto de 1551 en AGS, Estado, legajo 307, n. ${ }^{\circ} 364$. La carta del 27 de octubre de 1552 en AGS, Estado, legajo 309, n. ${ }^{\circ} 199$. Según ésta el ataque a Benidorm se produjo el 24 de octubre.

47 AGS, Estado, legajo $307, \mathrm{n}^{\circ} 324$ y 341. 
portantes. La primera era considerada fortísima, que sólo requería reparos en un pedazo de muro y dotar de más artillería, mientras que la última estaba altamente artillada. Vinaroz, Benicarló, Castellón, Burriana, Villareal, Nules, Almenara y Sagunto tenían defensas contra corsarios, pero no contra la armada turca, y en caso de que ésta apareciese sería necesario mandar a los habitantes de ellas que se retirasen tierra adentro a otras villas más fuertes. Así aconsejaba obras en núcleos del interior como Liria y Játiva. Guardamar necesitaba armas y municiones. En Gandía y Oliva se entendía en su fortificación. Cullera y Villajoyosa ni siquiera tenían defensas fiables contra corsarios, pero esto se corregiría pronto, según se tenía entendido. La torre de Oropesa, de don Juan de Cervellón, necesitaba de municiones y pólvora; Calpe, de Jerónima Pujades, requería algunos reparos ${ }^{48}$; Benidorm, de Alonso Fajardo, exigia, dada su importancia junto a la sierra de Bernia, su fortificación, reparación y provisión de artillería, municiones y guardia. Además aconsejaba cuidar el uso de caballos, traer 200 quintales de salitre para pólvora, así como carne y trigo para evitar el descontento. El apoyo a este informe desde el Reino de Valencia parecía amplio, pues fue acompañado de cartas de presentación del Arzobispo, los canónigos de Valencia, los diputados del Reino, el brazo militar y los jurados, entre otros ${ }^{49}$. Los resultados fueron inmediatos, el Rey ordenó que con parecer de los oficiales y electos de los estamentos se enviase un memorial de los lugares marítimos, y que las 13.000 libras que se tenían para pagar parte de los salarios de los doctores de la Real Audiencia se destinasen a la fortificación. El gobernador Juan Villarasa escribió al Príncipe indicando que el memorial debía realizarlo un ingeniero o alguna persona que mejor lo entendiese, y comunicaba el rechazo a la financiación propuesta ${ }^{50}$.

Por otro memorial sobre la guarda del Reino, probablemente de 1551, dado a su Alteza por el Maestre Racional de Valencia, sacado de las intenciones que le dio Juan de Villarasa, regente de la lugartenencia y capitanía general del Reino de Valencia, se exponía la necesidad de hacer las dos obras trazadas por el Maestre Racional: Villajoyosa y Cullera. En la primera, muy importante por estar cerca de Alicante y ser tierra poblada de moriscos, ya habían puesto 1.000 ducados los de la villa y otros tantos el

${ }_{48}$ Sobre las mejoras en la defensa de la baronia de Calpe, Benissa y Teulada véanse los documentos de 1551 transcritos en Banyuls I Pérez, Antoni; Boira I MaIQues, Josep Vicent; Lluesma I EsPanya: Arquitectura i control del territori. La defensa del litoral de la Marina Alta al segle XVI. 1996, Institut de Cultura Juan Gil-Albert. Ajuntament de Benissa, págs. 62-64 y 64-65.

49 AGS, Estado, legajo $307, n .^{\circ} 3, n .^{\circ} 344, n .^{\circ} 350, n .^{\circ} 354, n .^{\circ} 355, n .^{\circ} 370$.

so AGS, Estado, legajo $309, n .^{\circ} 137$. Información contenida en carta del Gobernador Villarasa al Príncipe del 20 de enero de 1552. 
Rey, que serían suficientes para acabar de fortificar el castillo de dicha villa, hacer un baluarte y un pedazo de muro hasta la iglesia, que era lo más necesario, aunque para cumplir todo lo trazado serian necesarios otros 4.000 ducados, a los que no podían hacer frente los del lugar. Lo mismo se decía en el caso de Cullera, pero aqui se aconsejaba que sólo diera el Rey otros 1.000 ducados por ser los de la villa más poderosos. Peñíscola estaba bien fortificada y sólo restaba terraplenar un lienzo de muro. Aconsejaba instar a los propietarios de Benidorm, Calpe, Denia y la torre de Oropesa a su cuidado y fortificación. En la costa proponía que se fortificase Valencia y Guardamar; mientras que en el interior se continuase con las defensas a la moderna iniciadas en el castillo de Morella, hacer murallas en Jijona contra los moros, y fortificar Játiva. Además aconsejaba que un ingeniero práctico en fortificaciones reconociera y trazase todo lo necesario, porque sólo así se haría bien y el dinero que en ello se gastare sería bien empleado; que se armasen las villas reales; se proveyesen de caballos el servicio de las guardas; se trajesen de Castilla 300 quintales de salitre para hacer pólvora, así como carnes y trigo para evitar alborotos; y que no se comerciase con Argel para evitar comprar mercancía robada, lo que estimulaba a más saqueos, y porque las relaciones siempre proporcionaban información ${ }^{51}$.

Los trámites fueron sucediéndose lentamente, hasta culminar en 155252. En las Cortes celebradas ese año el proyecto iniciado en las pasadas de 1547 se consolidó, pues se decidió que con los dineros procedentes del impuesto sobre la seda se haja de desprende en fortifiació, torres, atalayes, artilleria y municions de la costa del dit regne, y que les doze mil lliures que se han de traure del nou imposit de la seda, General y tacha serveixquen y se hajen de guastar en la guarda ordinaria de terra del dit regne y no per mar ${ }^{53}$. El 30 de mayo de 1552, por Real Orden, el Príncipe autorizó al Capitán General de Valencia a informarse si la muralla de Cullera, que debía proteger de los continuos ataques de corsarios berberiscos y otros infieles, no iba en detrimento de terceros, y si esto no sucedía que les concediese, en nombre de su Majestad, la licencia para construirla y les diese la traza para una mejor defensa ${ }^{54}$. El 8 de agosto del mismo año el

5t Transcrito en Banyuls I Pérez, Antoni; Boira I Maloues, Josep Vicent; Lluesma I Espanya: op. cit., 1996, Institut de Cultura Juan Gil-Albert. Ajuntament de Benissa, págs. 60-62. Procedencia AGS, Estado, legajo $307, n .^{\circ} 276$.

52 ACA, Cancillería Real, Registros, n. ${ }^{\circ} 4.282$, ff. 96-97 y 97v-98. Según Giner, Francesc: “Els totals de població en la història de Cullera», Anales del Centro de Cultura Valenciana. 1971, pág. 26. El Rey dio la autorización el 13 de enero de 1552, y cita como referencia ARV, Bailia, 287 Concretamente, las cartas y capitulaciones referentes a este asunto se encuentran en ff. 15-20.

Simo Santonja, Vicent Lluïs: op. cit., pág. 445.

${ }^{54}$ ACA, Cancilleria Real, Registros, n. ${ }^{\circ} 3.985$, f. $107 \mathrm{v}$. 
Príncipe comunicó al Bayle General de Valencia la asignación dispuesta por el Emperador para las fortificaciones de Cullera y Villajoyosa ${ }^{55}$, cuyo pago se autorizó el 26 de agosto de 1556 por haver ella gastado tanto para fortificarse ${ }^{56}$.

La decisión de amurallar la villa de Cullera tuvo una relación directa con el reciente acto de pillaje y la inseguridad que éste movió en la población. Asi lo recogia pocos años más tarde el cronista Martín de Viciana, que finalizó su obra con el castillo y villa de Cullera, que entonces contaba con 220 casas. Se hacia eco de los ataques y manifestaba como los de Cullera, por quitarse destos peligros y daños, en el mes de Setiembre año MD.liii. començaron de labrar el muro de cal y canto, con siete torreones y cxxxv. braçadas de contorno. Y a ix. de Febrero, año.M.D.Ivi. fue acabada de labrar con gasto de mas de .xi.mil ducados. (...) El castillo es fuerte y importante, y el Rey tiene por alcayde a don Miguel de Sanoguera, con .cl. escudos de salario ${ }^{57}$.

Siguiendo la información de la época, el estudio del trazado urbano de Cullera y la representación contenida en el proyecto de puerto en Cullera por el marqués de la Romana, se deduce que las murallas eran de cal y canto y formaban un pentágono irregular con siete torreones de forma troncocónica ${ }^{58}$. El proceso constructivo de estas murallas era suficientemente conocido en su cronología, pero no en sus protagonistas. Para algunos autores fue Juan Bautista Antonelli quien envió trazas en 1553 para reforzar la defensa de la ciudad y castillo, y su presencia se documenta intermitentemente durante tres años hasta el final de las obras. Si bien probablemente fuera Vicente Oliva el que quedó al frente de la misma ${ }^{59}$. Según otros autores, y utilizando distinta documentación, estas obras fueron realizadas por Joan Matalí e inspeccionadas por los piedrapiqueros Joan Batea y Miguel Porcar ${ }^{60}$. Sin embargo, como ya hemos señalado, en

55 ACA, Cancillería Real, Registros, n. ${ }^{\circ} 3.989$, ff. $2 v-3$.

s6 ACA, Cancilleria Real, Registros, $n .^{\circ} 4.009$, ff. 30v-31.

${ }^{57}$ ViCiana, Martín de: op. cit., págs. 370-371.

58 Archivo Histórico de Cullera $(=\mathrm{AHC})$, libro 119, Llibre de l'Administració dels Jurats, años 1557-1558. En 1557 ya se enumeran los siete torreones: Portal de Valencia o San Juan Evangelista, Santa Maria del Castillo, Santa Ana, San Jaime, Puente de San Juan Evangelista, San Jorge y Santa Marta. Fueron ya citados y algunos identificados por GiNER PEREPEREZ, Francesc: La Mare de Déu del Castell de Cullera. Estudio histórico. 1976. Ayuntamiento de Cullera; pág. 67.

59 Citado por Gómez-Ferrer Lozano, Mercedes: Arquitectura en la Valencia del siglo xvi. El Hospital General y sus artífices. 1998, Albatros, Valencia; pág. 208.

60 IBIzA I Osca, Vicent; Mut I Ruiz, J. Enric: Estudi sobre l'Església de Sant Vicent Màrtir de Guadassuar. 1995, Ajuntament de Guadassuar. 
1551 ya se indicaba que tanto las de Villajoyosa como las de Cullera, fueron trazadas por el Maestre Racional Joan Jerónimo Romani y de Scrivà ${ }^{61}$, y por el juicio que tuvo lugar en 1557 sobre la muralla construida, sabemos que sus trabajos se acordaron entre mossén Miguel Santander y la universidad de Cullera, y que avanzada la obra se subrogó a ésta el cantero Joan Matali. El libro de administración de los jurados de la villa de Cullera contenía entre los gastos de 1557 que Joan Guerau pagó trigo per al capellà de la muralla per obs de menjar a la sua gent quant feya la muralla. Por motivo similar se nombra a Joan Matalí ${ }^{62}$.

Considerar al Maestre Racional como el autor de la traza puede resultar novedoso, pero desde luego no descabellado. En los dos casos se trata de obras, a la antigua, con una tradición lo suficientemente amplia para que pudiera trazarla una persona práctica en el ámbito militar, aunque no necesariamente militar. El Maestre Racional, que era el inspector de las cuentas de los bayles, debía estar familiarizado con una de las partidas que más dinero se llevaba: la defensa. En 1552 visitó las villas reales y junto a maestros locales estableció diversas obras. No podemos pasar por alto, la ambigüedad de la palabra «trazada", pues en ocasiones aparece como sinónimo de acordada, dejando estipuladas las cantidades y plazos. Realmente, cuando en 1557 las dudas surgieron en Cullera sobre lo que se adeudaba a cada maestro se remitió a Joan Jeroni Romani y de Scrivà, maestre racional, lo qual ha molt entés en la fàbrica de la dita muralla. Pero, no cabe duda de que esta acepción es menos frecuente, y no excluye el diseño de obras sencillas. El propio Maestre Racional solicitó personas entendidas para que determinasen qué obras debían realizarse con criterios más modernos. Además, esta hipótesis parece confirmarse al considerar que el cargo de Maestre Racional fue ocupado más tarde por Vespasiano Gonzaga, como veremos de gran conocimiento militar y sobre fortificaciones.

En cuanto a la realización de las murallas, según el acuerdo Joan Matali debía recibir 56 sueldos por cada estado hecho. Al comenzar la obra recibió 200 coronas, en el transcurso de la misma cobró diversas cantidades y cuando finalizó en agosto de 1556 le prometieron que le abonarían el resto el siguiente año. En total reconoció haber recibido unas 2.500 libras, y en vista de que no se establecía lo que se le debía suplicó el nombramiento de canteros expertos que determinasen su trabajo. Joan Matalí nombró a Joan Batea, mientras que la Real Audiencia nombró a

${ }^{61}$ AGS, Estado, legajo $307, n .^{\circ} 276$

62 AHC, Llibre de l'Administració dels Jurats, libro 119 (1557-1558). 
Miquel Porcar para que representase a la villa. Los maestros realizaron un memorial ${ }^{63}$. El 19 de septiembre de 1557 el Real Consejo de la Real Audiencia obligó al síndico de Cullera a pagar a Matalí lo que se le debía. La villa contestó que no podía ponerse en contacto con su síndico, pero que si a alguien le correspondía pagar algo era a Miguel Santander que había cobrado más de 9.000 ducados, cantidad superior a la que realmente le correspondía por su trabajo. Por ello solicitaban que se desestimase la súplica de Matali o que se enviase al Maestre Racional, entonces Joan Jerónimo Romaní y de Scrivà, que tenía mucho que ver con la obra. Así pues, éste en la traza, y Miguel Santander con colaboración de Joan Matalí en la ejecución son los nombres que se asocian a las obras de las murallas de Cullera.

Pocos años después de acabadas las murallas, Vicente Oliva y Joan de Alacant redactaron un memorial sobre las obras que sería necesario acometer en el castillo y murallas de la villa. Concretamente, en estas últimas señalaban la necesidad de construir un foso alrededor, alamborar la base de los muros, proteger las torres cercanas a la montaña y dotar las torres de artillería ${ }^{64}$. A fin de cuentas se pretendía adaptar mínimamente unas murallas contra corsarios a la presencia de la artillería.

Las murallas de Cullera responden a las construcciones que en estos tiempos venian realizándose tradicionalmente, como las que hemos visto en la sierra de Espadán, pero las del Júcar se realizan en un momento de inflexión hacia unos criterios modernos de fortificación, sólo utilizados selectivamente por el mayor coste que suponía esta opción. Concretamente, y buscando un ejemplo de cada provincia, estas murallas presentan una cronología parecida a las de Villajoyosa y a las de Mascarell, pedanía de Nules. Muy parecidas en criterios son las primeras y las últimas. Las dos comienzan en 1553 y prácticamente finalizan al mismo tiempo - Mascarell en 1555 y Cullera en agosto de 1556- y pertenecen al tipo de murallas llamadas de lanza y escudo, pues estaban diseñadas para resistir un asalto convencional, sin artillería ${ }^{65}$. Más diferencias presentan las de

ARV, Real Audiencia, Procesos, Parte $2 .^{a}$, letra J, ap. n. ${ }^{\circ} 282$.

Concretamente la labor de Joan Matali en la muralla comprendia: hacia la parte del rio, desde el comienzo de la muralia de mossen Miguel Santander hasta la torre del portal de Valencia, comprendiendo esta torre y la de mossen Bou, por la que le correspondian 2.710 libras y 8 sueldos; y hacia la montaña, hasta la obra de mossen Miguel Santander, 224 libras.

${ }_{64}$ ARV, Maestre Racional, 9.171 bis, ff. 11-12.

is Gomez-Ferrer Lozano, Mercedes: op. cit., pág. 187. La obra de Mascarell, que debia seguir unas trazas ya hechas, la contrataron los maestros de albañileria Pere Climent y Jaume Garcés. Seguia una tradición medieval, pero como novedad presentaba torres y revellinos situados equidistantemente en el centro de los cuatro flancos de la muralla, baja disposición de troneras y sustitución de almenas por mosquetes. 
Cullera y Villajoyosa. Las primeras se realizaron en menos tiempo (15531556) y con 11.000 ducados, mientras que las de Villajoyosa (1544-1562) ascendieron a 17.000 ducados. Acabamos de ver el proceso constructivo de las murallas de Cullera, veamos a continuación las de Villajoyosa, que es algo más complejo. Hacia el año 1535 el Virrey de Valencia firmó con el maestro Martín las obras de fortificación de esta villa. Sin embargo, en 1538 se manifestaba su estado ruinoso, y las Cortes de 1547 propusieron realizar obras de gran envergadura, que fueron ordenadas más tarde. El cronista Martín de Viciana señaló que entre 1554 y 1562 se gastaron en ellas 17.000 ducados, pero precisamente este último año Juan Bautista Antonelli indicó al Rey la necesidad de emplear 4.000 ducados para crecela como conviene. En 1575 el propio ingeniero la describia como una cerca de la antigua reparada modernamente y con buena plataforma. Por tanto, la diferencia de precio entre la obra de Cullera y Villajoyosa encuentra explicación en que esta última tuviera algo en cuenta los avances de las nuevas armas de fuego a la hora de construir sus defensas, aunque fuera en una fase incipiente caracterizada por la utilización de muros terraplenados con caras externas alamboradas, torreones para artillería y cubos redondos ${ }^{66}$.

Por las mismas fechas aparecieron las primeras manifestaciones de la fase abaluartada, caracterizada por el uso en los ángulos de baluartes adelantados en disposición trapezoidal. Como muestra del enorme coste que suponían estas obras a lo moderno sirva comparar las murallas de Cullera con otra construcción de parecidas dimensiones y cronología: el castillo de Santa Pola, que don Bernadino de Cárdenas, duque de Maqueda, marqués de Elche y virrey de Valencia desde 1552 mandó construir a su propia costa y finalizaron en su mayor parte en 1557, aunque en 1562 Juan Bautista Antonelli aconsejara acabar de fortificarla. Las murallas de Cullera tenían 135 brazadas de contorno, siete torreones y costaron 11.000 ducados; el castillo de Santa Pola tenía 134 brazadas de contorno de muro muy grueso, baluartes a lo moderno y costó 23.000 ducados ${ }^{67}$. En 1575 Vespasiano Gonzaga la consideró obra impropia y de mucho gasto (...) y aunque es obra moderna y de muros gruesos no tiene terrapleno y tiene padrastro cerca. Pese a las poco favorables palabras del Virrey de Valencia, cosa muy habitual siempre que se juzgaba el trabajo de otro entendido en materia de fortificación que gozase de la confianza del Rey, se aprecia como la elección de una concepción u otra de defensa duplicaba el gasto.

66 Bevia I Garcia, Marius; Camarero Casas, Eduardo: op. cit.

6r Viciana, Martín de: op. cit, pág. 106. Además por esta fuente sabemos que mandó construir numerosas torres por la costa del Reino. Otros castillos construidos citados por Martin de Viciana son los de Jávea, hacia 1558, y los muros y baluartes de Alicante, desde 1550 a 1562. 
Por las exigencias defensivas del momento doña Juana de Austria, gobernadora del Reino por su padre Carlos I, el 9 de Octubre de 1554 recomendó a los jurados de la ciudad de Valencia reparar las defensas de la capital del Reino, edificadas hacía pocos años pero ya perdidas, de tal manera que en caso de necesidad no harian defensa, remitiéndoles a su vez a Bernardino de Cárdenas, duque de Maqueda y lugarteniente capitán general. Éste, además, realizó un plan de reformas de las torres costeras existentes, la construcción de otras nuevas y dictó las Ordenanzas de la Guardia Marítima del Reyno de Valencia, que fueron publicadas el 13 de febrero de $1555{ }^{68}$. De igual modo, ordenó hacer nuevas fortalezas y reparar otras antiguas, como Altea y Guardamar.

Una muestra más del enorme interés mostrado durante el virreinado del duque de Maqueda es que mandase al ingeniero Juan Bautista Calvi, que desde Lombardía había sido reclamado por el Emperador para que determinara las fortificaciones de las Islas Baleares, que reconociese las fortalezas del Reino de Valencia ${ }^{69}$. Una relación que presentó hacia comienzos de la década de los sesenta muestra la gran labor realizada hasta el momento, pues si bien de las torres de vigilancia de Valencia habla poco, lo cierto es que las utiliza como ejemplo: en toda la costa de Cataluña desde Colibre hasta los Alfaques de Tortosa seria menester hazer torres que se descubriesen la una a la otra, como si han hecho en la costa de Valencia, las quales hazen grandisimo efetto, pues protegen la navegación y la tierra. Incluso la financiación, en su opinión, era modélica, pues El gasto de las dichas torres se podría hacer a costa de los que reciven el beneficio, o como hicieron en Valencia que pusieron un derecho sobre la seda ${ }^{70}$.

Pero lo conseguido distaba de ser suficiente como lo refleja la petición $97^{\text {a }}$ de las Cortes de Toledo de 1560 , en las que los procuradores de las ciudades, y sobre todo el Maestre Racional y el canónigo Miguel

68 Salvador Lizondo, María Dolores: El Virreinato del Duque de Maqueda: Primer trienio (1553-1556). 1972, Tesis de licenciatura leida en la Facultad de Filosofía y Letras de la Universidad de Valencia. Transcribe en Apéndice Documental, n. ${ }^{\circ}$ VII, págs. 120-138 las Ordenanzas hechas por el llustrísimo Duque de Maqueda, lugarteniente y capitán general para lo que toca a la construcción y guarda de las torres y atalayas del reino nuevamente construidas.

69 ASHMM, Colección General de Documentos, 2-2-6-38 [2 hojas] y 2-2-6-40 [2 hojas]. Agradecemos a Javier Ferreras Fincías el ofrecimiento de esta noticia.

70 AGS, Estado, legajo $124, n .^{\circ} 25$. El informe no presenta fecha ni firma, pero la hoja que lo contiene presenta el nombre de este ingeniero y el año 1562. También Juan Bautista Antonelli señaló como ejemplar el mantenimiento de las torres del litoral de Valencia, pues de ello se encargaban los propios pueblos del Reino, sin merma para su Majestad (AGS, Guerra Marina, legajo 72 , n. $\left.{ }^{\circ} 295\right)$ 
Vich, mostraron al Rey el malestar por el descuido de las costas orientales y la necesidad de vigilar esta frontera con los corsarios del norte de África y el Turco. La sutil manera de reclamar esta atención fue mostrando los perjuicios que a la Corona reportaba tal situación. De este modo, expusieron que los daños de sus incursiones afectaban al comercio y al asentamiento de las gentes porque á cuatro ó cinco leguas del agua no osan las gentes estar; $y$ asi se han perdido y pierden las heredades que solian labrarse en las dichas tierras, y todo el pasto y aprovechamiento de las dichas tierras marítimas, y las rentas reales de $V$. M. por esto también se disminuyen, $y$ es grandísima inominia para estos reinos que una frontera sola como Argel pueda hacer y haga tan gran daño y ofensa á toda España. Por lo que solicitaban que la armada no se dedicase a otra cosa que a defender las costas ${ }^{71}$.

Juan Bautista Antonelli, conocedor de las fronteras hispanas con Francia, tempranamente señaló la necesidad de atender otra, pues por donde más suele temer España, y por donde más daño ha recibido y puede reçibir ha sido por el mar Mediterráneo, por haver havido por las costas siempre poderosos imperios y haverlos hoy ${ }^{72}$. Felipe II tempranamente envió la armada a recuperar Trípoli, a conquistar el Peñón de la Gomera, etc. Pero lo que es evidente es que puso remedio a la sensación de abandono y fragilidad de la costa oriental peninsular reforzando sus defensas marítimas. Las primeras medidas fueron ordenar al ingeniero que reconociera los castillos y lugares de la costa para determinar su fortificación y proveerlos de artillería. Los diferentes informes de Antonelli a lo largo de la década buscaron la versatilidad, pues proponía la construcción de una poderosa armada, con base en Barcelona, Cartagena y Gibraltar, y la creación de una milicia armada y ejercitada que acudiese en ayuda del lugar que lo necesitase. Pero también destacaba la importancia de una defensa estática que retuviese al enemigo mediante obras en ciudades, puertos y otros puntos importantes de vigilancia de la costa. Factores estos últimos en los que incidió más.

En 1561 Juan Bautista Antonelli tuvo que inspeccionar la costa. En el mes de octubre el ingeniero reconoció las sierras de Bernia y Espadán, acompañado de capitanes conocedores de la zona, de cuyo resultado envió varios informes escritos en italiano. En agosto de 1562 el Rey le ordenó

\footnotetext{
La transcripción completa de esta demanda se encuentra en LAFUENTE, Modesto: Historia General de España. Desde los tiempos primitivos hasta la muerte de Fernando VII. 1888. Montaner y Simón, Barcelona; t. IX, págs. 198-199.

AGS, Guerra Marina, legajo 72, n. 295.
} 
que volviese a inspeccionar la costa, pero incluyendo también los castillos del interior, y que lo hiciera junto al Maestre Racional Vespasiano Gonzaga, porque de lo que con el havemos tratatado tenemos entendida la platica e inteligencia que en esto tiene y el deseo de açertar a servirnos ${ }^{73}$. Ese mismo año enviaron un informe en el que aconsejaban la construcción de seis torres más y el refuerzo de las ya hechas. El ambicioso programa contemplaba inversiones en todos los puntos costeros, bien por obras, bien por armas y municiones, bien por ambas. Además, sugería fortificar los castillos interiores y que se trajesen numerosos caballos para custodiar el Reino de los moros o huir de ellos, si llegasen por sorpresa, y que se cuantificase el número de moriscos y de cristianos viejos. Dentro de estos últimos que se indicase la gente apta para pelear -entre 20 y 60 años-, y las armas de que disponian. Finalmente, señalaba la importancia de su ejercitación para la defensa del Reino y como milicia versátil que podría ser utilizada en caso de necesidad por el Rey ${ }^{74}$. Por las mismas fechas, como ya hemos indicado, Juan Bautista Antonelli comenzó el fuerte de Bernia, obra abaluartada que conectaba con las soluciones internacionales más avanzadas.

El 30 de marzo de 1563 presentaron un nuevo informe sobre la defensa de las costas valencianas. En resumidas cuentas el peligro era doble: uno real y cotidiano, que era el de los corsarios, y otro hipotético pero igualmente actual, que era el del desembarco de una poderosa armada, que además podia contar con el apoyo de un levantamiento de moriscos. El remedio contra corsarios era el que entendió el Duque de Maqueda, las torres de vigilancia, pero ahora se insistía en que fueran dotadas de artilleria. Como ha señalado Josep Vicent Boira, esta medida suponía que estas torres pasaran de un sistema medieval de alerta y prevención a una red de puntos fortificados y artillados capaces de resistir y desbaratar los intentos de desembarco de tropas no muy nume-

\footnotetext{
73 AGS, Guerra Marina, legajo 70, n. ${ }^{\circ} 165$. También hay información en los expedientes 164 , 166, y 217-220.

74 AGS, Estado, legajo 141.

Por carta del Rey al duque de Segorbe, virrey y capitán general de Valencia, fechada el 27 de agosto de 1562, se da a entender la intervención de Vespasiano Gonzaga, maestre racional, en lo que a defensas del Reino se refiere. Por ello, Felipe II le comisionaba para que junto a Juan Bautista Antonelli reconociesen el Reino de Valencia. AGS, Guerra Marina, legajo 70, n. 165. Cita esta carta, aunque destacando otros aspectos BOIRA MAIQUES, Josep Vicent: “Geografia i control del teritori. El coneixement i la defensa del litoral valencià al segle XVI: l'ínforme de l'enginyer Joan Baptista Antonelii", Cuadernos de Geografia. 1992, n. ${ }^{\circ}$ 52, págs. 183-199; concretamente pág. 185. El informe del Maestre Racional y Juan Bautista Antonelli, hacia 1562, ha sido transcrito en Banyuls I Pérez, Antoni; BoIra I MaIQues, Josep Vicent; Lluesma I Espanya: op. cit., 1996, Institut de Cultura Juan Gil-Albert. Ajuntament de Benissa, págs. 65-68.
} 
rosas ${ }^{75}$. El nuevo componente, la artillería, era tan fundamental que determinaba la distancia de las torres, pues cada una de ellas debia edificarse donde su tiro pudiera alcanzar el de la siguiente, introduciendo los mismos criterios de fuego cruzado que dominaban en los sistemas abaluartados de las fortalezas. La solución frente a una gran armada era defenderse por mar y fortificar los lugares y puertos donde ésta pudiera desembarcar. Aunque señalaba que cuantos más fueran mejor, porque con ello se podría entretener al enemigo hasta que llegasen refuerzos. Proponía dos casas de municiones (Valencia y Orihuela), proveer de artillería a la marina y organizar la caballería e infantería. Además establecía principios de estrategia militar en caso de un posible levantamiento de moriscos. Las plazas más importantes que requerían mayor defensa eran Alicante, Denia y Elche. Pero aconsejaba otras muchas ${ }^{76}$. Así pues, combinaba elementos estáticos y móviles, puesto que, por un lado, proponía un litoral fortificado atendiendo al nuevo peso de la artillería, con veinticuatro villas y ciudades, unas sesenta torres costeras artilladas y seis puntos de vigilancia; y, por otro, tenía en cuenta elementos móviles, como la guardia y la caballería. En definitiva, recogía aspectos ya citados anteriormente. El ambicioso programa del ingeniero fue suspendido a petición de las Cortes de 1564 debido a su enorme coste.

Juan Bautista Antonelli presentó otros informes que redundaron en lo mismo. Mantenía los mismos peligros y las mismas soluciones: una material, que consistía en reforzar las defensas, y otra humana, que, por ejemplo, consistía en crear una milicia formada por dos compañías a caballo ${ }^{77}$. Continuaba propugnando una defensa estática en lugar de móvil por criterios funcionales y económicos, pues las defensas terrestres siempre

$7^{5}$ BoIRa Maloues, Josep Vicent: op. cit. Según este autor el informe supone un cambio en la concepción territorial ante las nuevas exigencias de la guerra moderna y la reorganización de la estructura interna estatal, basada en el control total. Ofrece como procedencia AGS, E 329-1. Aunque cita sólo la contribución del ingeniero.

6 Asegurar la navegación con fortalezas en la isla de Santa Pola y Formentera. En el puerto de Moraira hacer una torre conforme a una traza que se les dio a los de Jávea para el rincón de San Antón, que hacían en esos momentos. Fortificar Villajoyosa, Benidorm, Guardamar, castillo y villa de Oliva, Gandía. En Cullera defender el río, fortificar el castillo y hacer una torre para asegurar el padrastro de Santa Ana. Fortificar el Grao, Valencia, Sagunto, Villareal, Burriana, Castellón de la Plana, Nules, Almenara, Peñiscola. Benicarló y Vinaroz. También propone poner en condiciones los castillos reales de la marina, así como los de Játiva, Orihuela y Morella. Finalmente da una relación de torres que deben hacerse y como proveerse éstas y las ya realizadas.

AGS, Guerra Marina, legajo 72, n. ${ }^{\circ} 182$. No existe plena certeza sobre la fecha de este informe. Por ejemplo, García Martinez, Sebastián: op. cit., 1977, pág. 50, señala como fecha posible 1563; mientras que CAMARA MUÑOZ, Alicia: "Las torres del litoral en el reinado de Felipe II: una arquitectura para la defensa del territorio (y II)", Espacio, tiempo y forma. Serie VII: historia del arte. $1991,{ }^{\circ} 4$, pág. 68 , apunta la de 1569 
permanecerían en su puesto y con menos coste. La defensa contra los corsarios debía realizarse mediante torres con guirnaldas para artillería que eliminasen los puntos donde éstos se resguardaban, avituallaban o desembarcaban. La defensa frente a una gran armada se conseguiria fortificando los principales puntos donde ésta pudiera desembarcar por su facilidad, como Puerto Nuevo de Elche, Alicante, Denia y Peñíscola, o bien por su importancia y prestigio, principalmente Valencia por ser capital del Reino. La mayoría del resto de puntos costeros importantes se encontraban ya cercados para evitar los saqueos, pero en ningún caso podrían repeler la invasión de un ejército. Éste era el caso de Guardamar de Segura, Villajoyosa, Benidorm, Altea, Calpe, Oliva, Gandía, Cullera, Sagunto, Cañizares, Almenara, Villarreal, Castellón, Nules y Oropesa.

Las cosas cambiaron pocos años más tarde. Entonces Íñigo López de Mendoza, marqués de Mondéjar, conde de Tendilla y virrey de Valencia, ante el temor general que provocó la pérdida de Túnez y La Goleta, consiguió de los estamentos del Reino 100.000 libras para la fortificación de la $\operatorname{costa~}^{78}$. El memorial que él mismo redactó, la incansable actividad de Vespasiano Gonzaga y de los ingenieros militares establecidos desde hacía años en el Reino, y la llegada de otro, muestran cómo durante este año se reavivó notablemente la preocupación por la defensa de los lugares marítimos del Reino de Valencia. El nuevo ingeniero al que hacíamos mención es Fratin. Por diversa correspondencia sabemos que a finales de 1574 don Pedro de Velasco y el capitán Fratin debían embarcar hacia Alicante para que éste diera su opinión sobre las trazas dejadas por J. B. Antonelli, y que la Real Audiencia pretendia seguir. Ante el retraso del ingeniero y capitán genovés el trayecto hubo de realizarse por tierra, lo que permitió que las opiniones de Fratin se extendieran a otros enclaves. Así reconoció el Grao de Valencia y, por petición del marqués de Mondéjar, Capitán General de Valencia, las defensas de Cullera y Denia ${ }^{79}$.

Junto a los ingenieros un alto representante de la administración territorial valenciana delegada del poder real, adquirió un gran protagonismo. Vespasiano de Gonzaga Colonna, duque de Sabbioneta y de Traietto, marqués de ostiano, conde de Fondi y de Rodrigo, tenía una gran experiencia como militar y comitente de obras militares cuando ocupó los cargos de maestre racional, primero, y virrey de Valencia, después. Nació en Sabbioneta, cerca de Parma. Muerto su padre Luis Gonzaga al servicio del

Camara Muñoz, Alicia: op. cit., 1991, n. ${ }^{\circ} 4$, pág. 69.

AGS, Guerra Marina, legajo 78, $n .^{\circ} 17,22$ y 33-35. El memorial del Marqués de Mondéjar en el expediente $n{ }^{\circ} 18$. 
Emperador, el Duque de Calabria, entonces Virrey de Valencia, en 1546 le encomendó al Emperador para que le sirviera como militar ${ }^{80}$. Desde 1556, con la colaboración de Girolamo Cataneo y Bernardo Panizzari realizó de nueva planta la construcción de la ciudad fortificada de Sabbioneta, compuesta de baluartes ataludados. Durante comienzos de la década de los sesenta, entonces era Maestre Racional de Valencia, viajó junto a Juan Bautista Antonelli, reconociendo las defensas del Reino de Valencia, pues tiene plática e inteligencia en esto y el deseo de servirnos, según palabras del propio Rey. Fue Capitán General de la infantería italiana en Piamonte y Lombardía. Defendió el puerto de Cartagena en 1570, junto a Juan Bautista Antonelli. Ese mismo año, ambos reconocieron la costa de Murcia. Aquí sus diferencias no podían disimularse: discrepan en el número, el material y la forma de torres. En 1571 fue nombrado Virrey de Navarra y comenzó la fortificación de Pamplona. En 1574 se encargó de las fortificaciones de Orán, Mazarquivir, Melilla, Gibraltar y Cádiz. En 1575 fue nombrado Virrey de Valencia, en 1578 Virrey de Nápoles y en 1588 plenipotenciario en Praga. Murió en 1591.

El entendimiento de Vespasiano Gonzaga en materia de defensas era harto dilatado. Su nombramiento como Virrey de Valencia en un momento de gran actividad defensiva no resulta casual. Menos si tenemos en cuenta que uno de sus primeros cometidos fue visitar la costa sur del Reino, poblaciones que por orografía y número de moriscos revestían mayores dificultades de defensa. El 30 de septiembre de 1575 firmó el informe de su inspección de la costa hacia Poniente, y el 19 de diciembre la de la costa hacia Oriente ${ }^{81}$. En

AGS, Estado, legajo 297, n. ${ }^{\circ}$ 157. Presentamos a continuación su transcripción:

Muy alto y muy poderoso señor.

Vaspasiano levador desta carta es hijo de don Luys de Gonzaga mi primo que murió en serviçio de su Magestad y siguiendo las pissadas del y de los suyos va en tan tierna hedad a emplear lo mejor de su vida en servicio de vuestra Alteza y porque es bien inclinado y tiene tan buenos desseos y prinçipios que no dexara de ser hombre de bien si vive. Suplico a Vuestra Alteza le mande favoreçer en todo lo que buenamente hoviere lugar que toda la merced que se le hiziere recibire yo por muy propia de Vuestra Alteza cuya muy alta y muy poderosa persona y estado guarde Nuestro Señor y acresçiente como su Real coraçón dessea. De Valencia a VIII de enero de MDXXXXVI años.

Muy humilde servydor que sus reales manos besa.

Don Fernando de Aragón.

B. Reproduce integramente el informe MATEU IBARS, Josefina: Los virreyes de Valencia. Fuentes para su estudio. 1963, Ayuntamiento de Valencia; págs. 154-161. Procedencia AGS, Guerra Marina, legajo 79, n. 102 . También citado, aunque con diferente fuente, por GiNER Pereperez, Francesc: El castell de Cullera a la segona mitat del segle XVI, 1968, Centro de Cultura Valenciana, Valencia; pág. 15 (procedencia Biblioteca Central e Histórica de la Universitat de València, Manuscrito $1.055, f, 119$. Actualmente este centro se halla cerrado y no se han podido cotejar los documentos). Numerosos autores han utilizado los informes de Vespasiano 
resumidas cuentas pretendía concentrar los gastos en escasos centros, como Alicante, Denia y Peñiscola, aquellos en los que una armada enemiga pudiera desembarcar, mientras que porque las demás son de poca consideración y no an menester más reparo de quanto estén seguros que una noche no se lleben los moros los habitadores. Junto a las grandes puertas de entrada al Reino, los figurados lienzos de la muralla de la costa serían las sucesivas torres de vigilancia, de las que recordaba la necesidad de la de Villajoyosa-Benidorm, la de Calpe, la de Oliva-Gandía y la de la desembocadura del río Júcar. Estas propuestas las reafirmó en varias cartas del año siguiente $^{82}$. La de la desembocadura del Júcar evitaría que los corsarios se acercasen a tomar agua del río, y permitiría controlar las embarcaciones de moriscos, que en este punto eran las más numerosas de todo el Reino ${ }^{83}$. El Rey ordenó a Vespasiano Gonzaga su construcción el 30 de marzo de 1576 ${ }^{84}$. La torre fue levantada en el margen derecho del Júcar, junto a la desembocadura - si bien una riada posterior cambió el curso y hoy se encuentra algo alejada-, y se llamó del Marenyet. En la obra con gran probabilidad participó en sus inicios el cantero Jerónimo Lavall, y fue acabada en 1577 , como así lo indica la inscripción de su entrada (Figura 3).

Vespasiano Gonzaga inspeccionaba los mismos puntos que hizo años antes como maestre racional en compañía de Juan Bautista Antonelli, pero ahora lo hacía solo y con sugerencias tan drásticas como derribar el novísimo fuerte de Bernia, la obra de su antiguo compañero de viaje y con el que tantas veces se enfrentó. Su trayectoria evidencia, por tanto, que estuvo detrás de muchas decisiones constructivas, e incluso que actuó como tracista. De hecho en tierras italianas participó en la confección de su ciudad ideal Sabbioneta, y en tierras hispanas lo confirma una carta sin fechar enviada al Rey que dice: Enbio a V. M. un modelo de relieve de la ultima obra que he echo en España que es la fortificaçión de Peñiscola, harto importante plaça para estos tres Reynos (...) Holgare mucho que contente a V. M. y una traça que enbio también en papel al menos syno havere açertado toda la culpa será mia porque no he tenido otro ingeniero a la oreja como en otras ${ }^{85}$.

Gonzaga. Probablemente el más reciente sea el de BoIra MaIQuEs, Josep Vicent: “Viles, castelis $i$ torres de guaita al litoral valencià del segle XVI. Les cartes del virrei Vespasià Gonzaga Colonna", Afers, 1994, n. ${ }^{\circ} 19$, págs. 555-574. Destaca no sólo sus conocimientos militares y constructivos, sino también los de la situación económica y administrativa del Reino. Da como signatura BUV, Ms-5

a2 AGS, Guerra Marina, legajo $81, n .^{\circ} 37,41$ y 42 . La frase en cursiva corresponde a una carta de 7 de marzo de 1756.

${ }^{83}$ AGS, Guerra Marina, legajo $79, n^{\circ} 100$ y 101

B4 AGS, Guerra Marina, legajo 82, $\mathrm{n} .^{\circ} 54$.

as AGS, Guerra Marina, legajo $90, n .^{\circ} 20$. 
Defensas a la antigua y a la moderna en el Reino de Valencia...

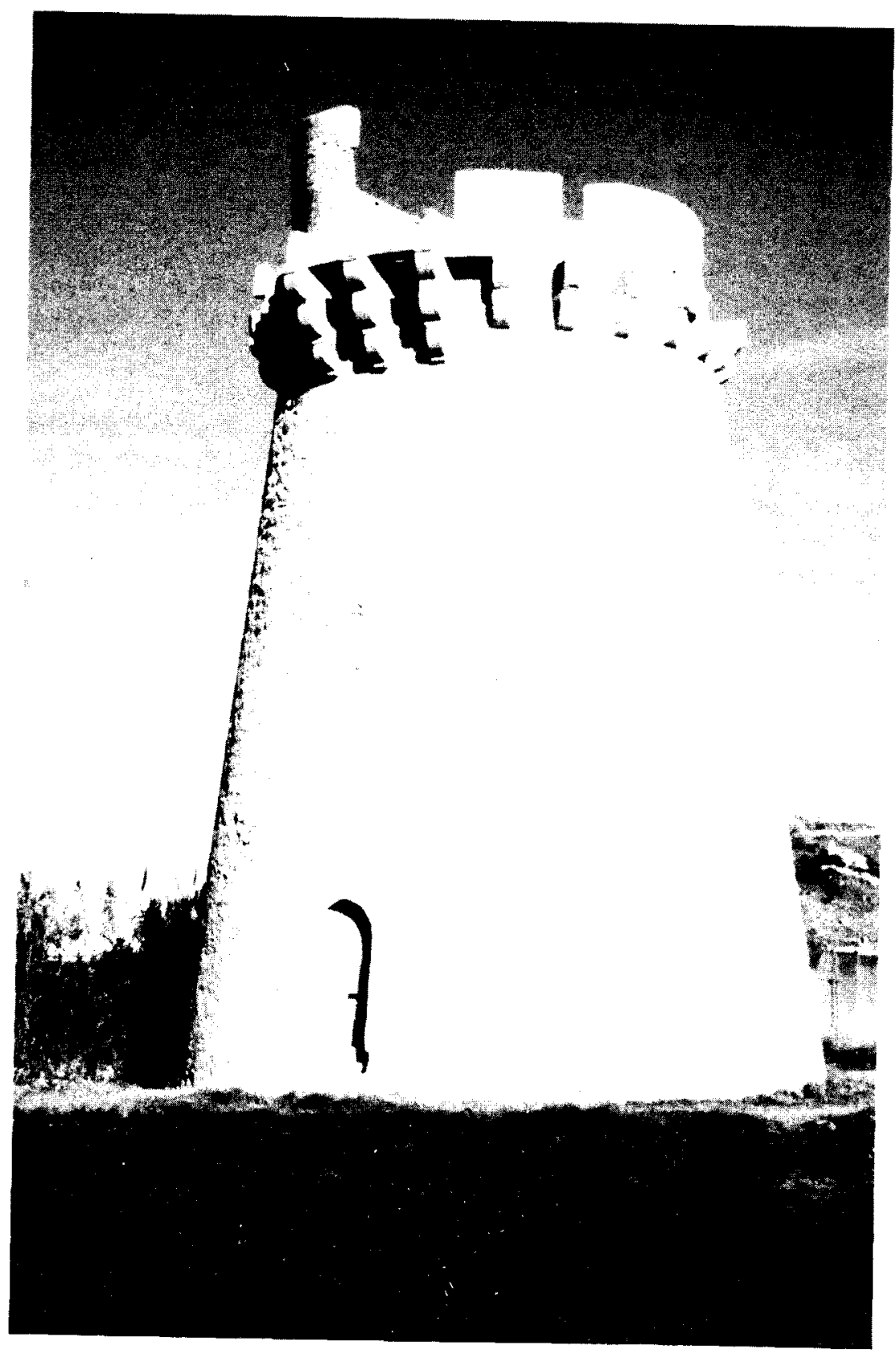

Figura 3. Torre del Marenyet en la antigua desembocadura del río Júcar, Cullera. Sobre el acceso inscripción conmemorativa de Vespasiano Gonzaga. 
Vespasiano Gonzaga envía maqueta y diseños, que no eran los únicos que trazó, sino los últimos hasta la fecha de la carta. Continuaba la labor de tracista de defensas de su predecesor en el cargo de maestre racional, Joan Jeroni Romaní y de Scrivà, aunque las diferencias entre ambos son evidentes. Mientras el primero en el puesto se encontraba más cómodo entre los principios tradicionales, y solicitaba ayuda para otras obras de mayor envergadura, Vespasiano Gonzaga trae de manera decida los nuevos principios defensivos y solicita autonomía de criterios en las obras más ambiciosas. Así lo muestra la ironía con la que se refiere a los ingenieros - probablemente a los Antonelli- en su oreja, lo que es síntoma inequívoco de su malestar. De cualquier modo esta forma de proceder de Felipe II con ingenieros, capitanes y otros funcionarios que por mandato real inspeccionaban lo ya inspeccionado no hacía más que trasladar al ámbito constructivo de la defensa, el consejo que su padre le dio de no mostrar predilección por ningún secretario para una correcta administración, implantando un sistema de competencia que supuestamente redundaría en beneficio del Estado. Pero no cabe duda de que en ocasiones era poco operativo, pues pronto se caía en disputas bizantinas que sólo encontraban como medio para mostrar su capacitación el señalar las carencias del colega o compañero de viaje. Aunque esto no quita que en ocasiones el reconocimiento saliera a relucir. Así, según Bautista Antonelli, el capitán general Vespasiano Gonzaga era más inteligente que ninguno en fortificación ${ }^{86}$. De hecho, propuso juegos proyectuales para Benidorm, Denia y Alicante ${ }^{87}$.

A comienzos del siglo XVII Gaspar Escolano ofrecía esta información de Cullera: es hoy en dia Villa Real de hasta trescientas casas, con su muralla de piedra hecha en el año mil y quinientos cinquenta y seys: $y$ en ella sus saeteras $y$ troneras a trechos, $y$ siete Torres bien artilladas: donde entre otras pieças, tienen un sacre que arroja bala de peso de nueve libras, $y$ alcanza dos millas y media: y por el peligro de corsarios del mar, entran cada noche de guardia en tres torreones y la pasan en perpetua centinela ${ }^{88}$. Al comparar las palabras de $\mathrm{M}$. de Viciana con las de $\mathrm{G}$. Escolano se desprende: por un lado, que en menos de cincuenta años el número de casas había aumentado considerablemente, probablemente con el estímulo de la muralla, que alejaba una de las principales causas de

a Camara Muñoz, Alicia: "La fortificación de la monarquia de Felipe II". Espacio, tiempo y forma. Serie VII: historia del arte. 1989, Serie VII, Historia del Arte, n. ${ }^{\circ}$ 2, págs. 73-80; cita en pág. 74.

${ }^{87}$ Bevia I Garcia, Marius; Camarero Casas, Eduardo: op. cit.

вH Escolano, Gaspar: op. cit., 1611, Segunda Parte de la Década Primera, libro VI, capítulo XXIV, columnas 220-221. 
retracción de población ${ }^{89}$; por otro, que el castillo ni siquiera se menciona y la importancia defensiva se centra en las propias murallas de la villa y en la vigilancia mediante tres torres. Las medidas de prevención y vigilancia de la costa correspondian a las torres de defensa y en ellas se centraban las atenciones de mantenimiento. Los puntos fuertes eran contados.

El Reino de Valencia comenzó a quedar al margen de la prioridad estratégica. Así, el informe fechado el 26 de Febrero de 1605, que el comendador Tiburcio Espanochi, con la aprobación de don Juan de Acuña Vela, capitán general de la artillería, dirigió a su Majestad sobre las fortificaciones de España, calificaba como llaves de España en el Mediterráneo: Gibraltar, Cartagena y Perpiñán ${ }^{90}$. Hacia mediados de siglo XVII la Guerra de Cataluña llevó a centrar las defensas en el norte de la provincia de Castellón, como Traiguera, mientras que en la segunda mitad los esfuerzos se centraron en las principales plazas. En 1656 el duque de Montalvo, virrey de Valencia, en previsión de los ataques de los ingleses aconsejó fortificar y amunicionar Peñíscola, Denia, Alicante y Guardamar ${ }^{91}$. En 1663 la consulta del consejo de guerra sobre la fortificación de los puertos marítimos del Reino de Valencia, sólo incluyó las plazas de Peñíscola y Alicante ${ }^{92}$. En las Ordenanzas del Cuerpo militar de la Costa maritima de este Reino de Valencia de 1673, redactadas por Vespasiano Manrique Gonzaga, conde de Paredes, se actualizaron aunque con escasas variaciones las redactadas hacía más de cien años, mostrando la validez del sistema de defensa ${ }^{93}$.

Pese a la concentración en las defensas frente a una gran armada, la inseguridad ante los saqueos continuó durante años. Fray José de Sigüenza hombre de la segunda mitad del XVI y principios del XVII, describía esta situación al decir que los piratas molestan aquella costa conti-

Sobre la evolución demográfica de Cullera desde época medieval hasta la actualidad véase Giner Pereperez, Francesc: op. cit., 1971, págs. 19-48. El estudio muestra una fuerte caída de la población del siglo $x V$ a $x \mathrm{~V}$, pero coincidiendo con la construcción de las murallas, se aprecia un nuevo crecimiento y consolidación de la población que se mantendrá constante a lo largo del siglo XVII. A partir del segundo cuarto del XVIII se inicia un ascenso constante hasta avanzado el siglo XX.

9! ASHMM, Sección José Aparici, Rollo 3, Tomo XI, págs. 2-15, n. ${ }^{\circ}$ de orden en Catálogo 1.594. Una vez más, agradecemos a Javier Ferreras Fincias que nos haya facilitado esta noticia. AGS, Negociado de Guerra, legajo 1.883.

92 $\quad$ AGS, Negociado de Guerra, legajo 2.028.

9. Ordenanzas del Cuerpo militar de la Costa maritima de este Reino de Valencia, traducidas del idioma valenciano al castellano y reformadas en 28 de junio de 1673. 1673, Jerónimo Vilagrasa, Valencia. Publicadas en CASTAÑEDA y Alcover, Vicente: Relaciones geográficas, topográficas e históricas del Reino de Valencia, hechas en el siglo xvm a ruego de D. Tomás López. 1919-1921-1924, Tipografia de Revista de Archivos, Madrid, vols. III, concretamente 1924, t. III, Apéndice I, págs. 91-140. 
nuamente, y con la codicia de los rescates no auia punto de seguridad, situación que se agravaba con los moriscos, que ha auido siempre mucho desto en aquel reyno, aconteciendo vezes no poderse salir de casa sin manifiesto peligro, ni caminar sino en quadrillas ${ }^{94}$. Los ataques berberiscos fueron una constante y marcaron las mentes del momento hasta el punto que en 1599, durante las fiestas celebradas con motivo de la visita de Felipe III y su hermana a Oliva y Gandía, al entrar la comitiva real en el condado de Oliva, se representó por sorpresa un simulacro de asalto de piratas berberiscos, tan a lo vivo que llego a provocar desmayos entre las damas de la Corte ${ }^{95}$. Incluso tras la expulsión de los moriscos las poblaciones con cercas de lanza y escudo permanecieron como instrumentos útiles contra corsarios, bandoleros, desórdenes y pestilencias, y marcaron el perfil de poblaciones, en ocasiones no sin cierto realce estético. Así, Vespasiano Gonzaga dijo de las de Alicante cerca nueva es de cubos redondos, con almenas y más parece que sirven a hornato que a necesidad.

94 Sigüenza, Fray José de: Segunda (tercera) parte de la historia de la Orden de San Gerónimo. 1600 - 1605, Imprenta Real, Madrid; págs. 75 y 120.

9s Camarena, José: Historia del distrito de Gandia. 1965, Fomento de Agricultura, Industria y Comercio de Gandía; págs. 54-55. 